\title{
Development of Eco-friendly Dyeing Process Based on Caesalpinia sappan L. Bark, Cocos nucifera Fiber and Leucaena leucocephala Leaves
}

\author{
N. Kusumawati a, ${ }^{\text {, }}$, M.M. Sianita ${ }^{\text {a }}$, A.B. Santosa ${ }^{\text {b }}$, Supari Muslim ${ }^{\text {b }, ~ A . R . ~ S e l l a ~ A u l i y a ~}{ }^{c}$ \\ ${ }^{a}$ Departement of Chemistry, Universitas Negeri Surabaya, Ketintang, Surabaya, 60231, Indonesia \\ ${ }^{b}$ Departement of Electrical Engineering, Universitas Negeri Surabaya, Ketintang, Surabaya, 60231, Indonesia \\ ${ }^{c}$ Departement of Chemistry, Airlangga University, Mulyorejo, Surabaya, 60115, Indonesia \\ Corresponding author: ${ }^{n}$ kusumawati82@yahoo.com
}

\begin{abstract}
Natural dyes have begun to regain attention due to biodegradable nature and low negative impact on human health and the environment. Besides, the continuous development of color shades variants from several natural sources of newly available abundant natural dyes and their ability to produce high color intensity and high wash fastness has become a major consideration of their use in textile dyeing. This study has evaluated the potential utilization of Caesalpinia sappan L bark, Cocos nucifera fiber, and Leucaena leucocephala leaf as a single and combination natural dye material. In particular, the extracts of these natural dye materials are used to dye the cotton fibers by involving mordanting stages using alum and fixation using iron (II) sulfate, alum, and calcium oxide compounds. The quality of the resulting dyeing was evaluated by the intensity of the color and wash fastness against wet washing. The dyeing results showed the appearance of varied shades of color with the dominance of the typical reddish color of Caesalpinia sappan L. While the results of the analysis using Diffuse Reflectance Ultraviolet (DRUV) and the wash fastness using the staining scale method showed high color dyeing with the color intensity in the range $53.55 \%-94.34 \%$ with wash fastness in the staining scale range 2 (less) 4 (good). Specifically, in contrast to the behavior of dye AB, the AC staining scale increases with increasing dye $\mathrm{C}$ added (up to $50 \%$ ) and decreases when dye $\mathrm{C}$ added increases to $75 \%$ (dye AC3).
\end{abstract}

Keywords - Textile; natural dyes; Caesalpinia sappan L; Cocos nucifera; Leucaena leucocephala.

Manuscript received 5 Oct. 2020; revised 27 Nov. 2020; accepted 3 Feb. 2021. Date of publication 31 Oct. 2021. IJASEIT is licensed under a Creative Commons Attribution-Share Alike 4.0 International License.

\section{INTRODUCTION}

Over the past few years, many industries, particularly the textile industry, have been heavily criticized for their role in polluting the environment [1], [2]. This is directly related to the textile industry's use of large amounts of synthetic dyes [3]-[5]. Several synthetic dyes facts that are considered more economical have superior fastness properties, varied color shades, and greater reproducibility has become the main background of the dominance of the synthetic dyes used in various industries [6]-[8]. However, dyeing using a large number of synthetic dyes is known to have the potential to produce a toxic waste that negatively affects the aquatic ecosystem and has mutagenic, carcinogenic, and toxicological properties in human health [9]-[13]. In the increasing phenomenon of environmental destruction and deterioration of the world's public health quality, environmentally friendly non-toxic natural dyes reappear as a choice of 'Green
Chemistry' as a substituent/complement of synthetic dyes to some extent [14]. In recent years, large-scale research [15][17] has been undertaken globally to explore the natural dye preparation procedures from a variety of sources, both plants, animals, and minerals as well as optimizing its utilization by suppressing its limitations on textile fiber dyeing.

Nowadays natural dyes primarily derived from plants; because of its abundant availability, biocompatibility, low toxicity, green approaches, and eco-friendly properties have gained worldwide popularity for use in textiles [18]-[21]. Natural dyes can be obtained from the extraction of certain parts of the specific plant [22]-[28], such as roots, rhizomes, seeds, bark, leaves, flowers, or fruit. Many plant parts such as secang (Caesalpinia sappan L.) bark, coconut (Cocos nucifera) fibers, and lamtoro (Leucaena leucocephala) leaf can be used as a source of natural dyes [29]-[33].

Water-soluble braziline flavonoids are the main source of red dye on Caesalpinia Sappan Linn. or Sappanwood (family 
Leguminosae) [34]-[36]. The extract has been used extensively as a natural dye, especially in the textile industry due to its low toxicity and low cost [37]-[39]. Sappanwood extracts in addition to functioning as a natural red dye, also show great benefits as antibacterial agents [38], [40]-[42], antioxidants [38], [43]-[45], and pharmacological activity [46]. Also, braziline is easily oxidized by light to form a very red brazilein [35], [38]. Characterization with UV-Vis spectroscopy and $\mu$-spectrofluorimetry revealed that in its acid form, brazilein chromophores provide maximum absorption, excitation, and emission respectively at wavelengths of 446, 475 and $536 \mathrm{~nm}$ and 540, 548 and 560 $\mathrm{nm}$ when deprotonated. When complexed with $\mathrm{Al}^{3+}$ the wavelength values are changed to 510,520 , and $585 \mathrm{~nm}$, respectively.

Cocos nucifera or coconut fiber has fiber with a strong structure that is not easy to rot or moldy and durable [45], [47]. Indonesia is the biggest coconut-producing country in the world [48]. But unfortunately, coco fiber processing has not been done optimally, where every year only $15 \%$ of the total abundance of processed coconut husk, while the rest will be left to accumulate as waste that will eventually dry up and then burned [49]. This condition is unfortunate, considering coconut husk is part of the coconut husk that can be used as a natural dye because of the flavonoid type water-soluble tannin content. This dye will give off a reddish-brown color and gradation depending on the type of mordant and fixer compound used [50]. Characterization with UV-Vis spectroscopy revealed that Cocos nucifera fiber extract provides maximum absorption at wavelengths of $385.41 \mathrm{~nm}$ and $380.79 \mathrm{~nm}$ when complexed with $\mathrm{Al}^{3+}$.

Leucaena leucocephala, commonly called petai china, is a kind of shrub from the Fabaceae family (Leguminosae, legumes). Leucaena Leucocephala is a plant that is easy to find in the tropics, such as Indonesia. Similarly, with coconut husk, Leucaena leucocephala leaf material has not been used as much of the fruit that is widely used as a raw material of traditional Indonesian food. This material contains many phenolic compounds in high concentrations, especially types of tannins and mimosine, making it a potential natural dye material. As with most tannins, tannin chromophores in Leucaena leucocephala leaf will also produce a reddishbrown color and a gradation, according to the type of mordant and fixer applied [51], [52]. Characterization with $U V$-Vis spectroscopy revealed that Leucaena leucocephala leaf extract provides maximum absorption at wavelengths of $417.84 \mathrm{~nm}$ and $387.50 \mathrm{~nm}$ when complexed with $\mathrm{Al}^{3+}$.

Dyeing using natural dyes is generally accompanied by several problems such as narrow shade range and lower fastness. The utilization of mordant compounds is one effort that can be done to overcome these problems. In addition to increasing the affinity between the dye compound and the fabric fibers, the application of mordant may cause hue changes of a number of specific dyes. Application of different mordant types to the same dye compound can darken, brighten, or alter the final color significantly [53], [54]. The colorimetric properties of the dyeing results including lightness $\left(\mathrm{L}^{*}\right)$, redness-yellowness $\left(\mathrm{a}^{*}\right)$, blueness-greenness $\left(b^{*}\right)$, chroma $\left(c^{*}\right)$, hue $\left(h^{o}\right)$ and color strength $(\mathrm{K} / \mathrm{S})$ are strongly influenced by the chemical properties, both mordant and fiber compounds and the forming ability of metal complexes with dyes and fibers [55]. Mordanting is generally capable of improving dye performance by producing a wide spectrum of shades on a variety of natural fibers as well as synthetic fibers with increased color intensity and fastness [56], [57].

One of the colored fabric qualities can be seen from the fastness. Besides mordanting optimization, fixation is another way that can be done to improve fastness through the color locking process on fiber. Fixation is generally done by adding metal complex materials, such as iron (II) sulfate $\left(\mathrm{FeSO}_{4} .7 \mathrm{H}_{2} \mathrm{O}\right)$, aluminum sulfate, or alum $\left[\mathrm{Al}_{2}\left(\mathrm{SO}_{4}\right)_{3} .18 \mathrm{H}_{2} \mathrm{O}\right]$ and calcium oxide $(\mathrm{CaO})$. However, the application of the fixation process in the final stages after dyeing also has the potential to darken, brighten, or alter the color significantly as it does with mordanting. This is triggered by the presence of several chromophores in the fixer compound used, which will lead to the appearance of a specific hue when the absorption of light occurs [58]-[61].

The current research focuses on producing dyed fabrics using red pigments from sappanwood extract and reddishbrown producing pigments from Cocos nucifera fiber and Leucaena leucocephala leaf extract separately and as a combination dye. This study is the first report on the dyeing carried out by combining the braziline and tannin compounds, the two dominant pigments in the three raw materials used. To find out the effect of both pigments' combination on the quality of cotton dyeing, the color production is done through the use of composition $75 \% / 25 \% ; 50 \% / 50 \%$; and $25 \% / 75 \%$ both for a combination of sappanwood bark extract with Cocos nucifera fiber and Leucaena leucocephala leaf extract. Meanwhile, the color production using a 100\% composition in sappanwood bark, Cocos nucifera fiber, and Leucaena leucocephala leaf extract was applied as a comparative color needed to determine the extension of the color spectrum resulting from the pigment combination process. Besides, achieving optimum color strength and creating a wide colors spectrum is done by forming bridge compounds between cotton and pigment using mordant alum, which has aluminum as a central atom with a three-valence positive charge application color-locking using 3 types of fixer compounds. Furthermore, the interaction between fabric fibers, mordant alum, combinations of pigments, and fixer compounds, which have not been previously reported, have been investigated. An analysis of the effect from three different fixer compound uses was also performed to determine the suitability of interactions between pigment combinations with fixers in generating color spectrum expansion and increased strength and fastness.

\section{MATERIAL AND METHOD}

\section{A. Washing Process}

Cotton fibers to be dyed must go through a washing process to remove contaminants attached. Thus, the appeal of mordant alum to fabric fibers increases. The following procedure does the washing of cotton fibers. The 2.57-gram cotton fiber is immersed in a 2 gram/liter Turkey Red Oil (TRO, Dunia Kimia, Indonesia) solution for $6 \mathrm{~h}$. Furthermore, three times were rinsing using distilled water to remove the mordant residue that does not interact with cotton fibers. The cotton fiber washing procedure was ended by drying the cotton fibers in the open air for 24 hours [3], [11]. 


\section{B. Mordanting Process}

After going through the washing stage, the cotton fiber preparation process continues with the mordanting using aluminum sulfate $\left(\mathrm{Al}_{2}\left(\mathrm{SO}_{4}\right)_{3} .18 \mathrm{H}_{2} \mathrm{O}\right.$, Brataco Chemistry, Indonesia) and soda ash $\left(\mathrm{Na}_{2} \mathrm{CO}_{3}\right.$, Water, Indonesia). The mordant solution is made by dissolving 8 grams of alum and 2 grams of soda ash in 1 liter of distilled water. The stirring process using a magnetic stirrer was applied to ensure the homogeneity of the solution. The solution is then heated to boiling, and into it is added 2.57 grams of cotton fiber. The process of heating process continued for 1 hour. To optimize the interaction that occurred with alum mordant, cotton fibers were left submerged in a mordant solution for 24 hours. In the next step, cotton fibers are rinsed (not squeezed) three times and then dried and ironed. Ironing of cotton fibers is done to get a uniform fiber orientation. After that, the cotton fibers are ready to be dyed using natural dyes [3], [11].

\section{Dyeing Process}

After going through the washing and mordanting, cotton fibers are ready to be dyed using water extract of Sappanwood bark (Dwi Jaya, Indonesia), Cocos nucifera fiber (Berkah, Indonesia), and Leucaena leucocephala leaf (Bengawan Solo riverbanks, Indonesia). Table 1 shows the operational conditions for the dyeing [11], while Table 2 shows the natural dyes extract compositions.

TABLE I

THE OPERATIONAL CONDITIONS FOR DYEING PROCESS

\begin{tabular}{cc}
\hline & Condition \\
\hline Material to liquor & $1 / 35($ gram $/ \mathrm{mL})$ \\
Temperature & Room temperature \\
The weight of cotton fiber & 0.85 gram \\
Dyeing time & 50 minutes \\
\hline
\end{tabular}

TABLE II

THE NATURAL DYES EXTRACT COMPOSITIONS

\begin{tabular}{cccc}
\hline & \multicolumn{3}{c}{ Compositions (wt.\%) } \\
\cline { 2 - 4 } & Sappanwood & $\begin{array}{c}\text { Cocos } \\
\text { nucifera }\end{array}$ & $\begin{array}{c}\text { Leucaena } \\
\text { leucocephala }\end{array}$ \\
\hline A & 100 & 0 & 0 \\
B & 0 & 100 & 0 \\
C & 0 & 0 & 100 \\
AB1 & 75 & 25 & 0 \\
AB2 & 50 & 50 & 0 \\
AB3 & 25 & 75 & 0 \\
AC1 & 75 & 0 & 25 \\
AC2 & 50 & 0 & 50 \\
AC3 & 25 & 0 & 75 \\
\hline
\end{tabular}

\section{Fixation Process}

To improve the fastness of natural dyes, after going through the staining stage, the cotton fibers must go through fixation using three types of fixers, including iron (II) sulfate $\left(\mathrm{FeSO}_{4} .7 \mathrm{H}_{2} \mathrm{O}\right.$, Nusa Indah Megah, Indonesia), alum, and calcium oxide $(\mathrm{CaO}$, Mitra Water, Indonesia). The fixer solution was prepared by dissolving 50 grams of each fixer material in 1 liter of distilled water. The solution was allowed to age for 24 hours and then from the solution was taken a transparent solution. The fixation process is carried out by immersing the cotton fibers in the fixer solution for 10 minutes. To determine the resulting color difference, a fixation of 0.85 grams of cotton fibers was performed in 30
$\mathrm{mL}$ of iron (II) sulfate, alum, and calcium oxide solution respectively. In the next step, each cotton fiber is rinsed three times using distilled water and then dried in the open-air [11].

\section{E. Characterization}

To determine the pigment characteristic in the water extract from Sappanwood bark, Cocos nucifera fiber, and Leucaena leucocephala leaf, wavelength analysis was done with maximum electromagnetic wave absorption Pharmaspec UV1700 UV-Visible Spectrophotometer. The maximum wavelength region $\left(\lambda_{\max }\right)$ will show the dominant pigment contained in the water dye extract of each raw material. Each dye's CieLab coordinates ( $\mathrm{L}^{*}, \mathrm{a}^{*}, \mathrm{~b}^{*}$ ) were directly measured using a spectrophotocolorimeter (Tintometre, Lovibond PFX 195 V 3.2, Amesbury, UK). In this coordinate system, the $L^{*}$ value is a measure of lightness, ranging from 0 (black) to 100 (white); the $a^{*}$ value ranges from -100 (greenness) to +100 (redness) and the $b^{*}$ value ranges from -100 (blueness) to +100 (yellowness). Besides, at this stage, cotton fiber also analyzed the intensity and fastness to determine the quality of the colors resulting from the combination of pigment and three different fixer compounds. Color intensity analysis was performed using Shimadzu Diffuse Reflectance Ultraviolet (DRUV) UV-2401-PC Spectrophotometer, while the fastness analysis was performed using the staining scale method. The higher color intensity will generally result in lower reflection percentages in the analysis results using DRUV.

\section{RESULTS AND DISCUSSION}

\section{A. Dyes Extract Characterization}

A, B, and C dyes, each prepared as cotton fiber pigments by extracting dyes from Sappanwood bark, Cocos nucifera fiber, and Leucaena leucocephala leaf. Consequently, A dyes exhibit characteristic properties of the red-pink color of brazilein flavonoids, which appear as red chromophores as oxidized forms of braziline from Sappanwood bark (Fig. 1a). The red-pink color with maximum wavelength at $538.57 \mathrm{~nm}$, as shown in Fig. 3a, is red (a*) higher than 19.00 (Table 1). Meanwhile, $\mathrm{B}$ and $\mathrm{C}$ dyes exhibited characteristic properties with a typical reddish-brown tannin flavonoid, as shown in Fig. $1 \mathrm{~b}$ and Fig. 1c. However, compared to Cocos nucifera extract, Leucaena leucocephala extract showed a darker color. Also, the occurrence of reddish-brown Cocos nucifera showed redness in color $\left(\mathrm{a}^{*}\right)$ for 12.16 . The redness in color values is lower than Leucaena leucocephala, which has a* value of 17.40 .

The UV-Vis spectrum of the AB1 dye extract shows the maximum absorption at the wavelength $538.34 \mathrm{~nm}$ with a bathochromic shift $(0.23 \mathrm{~nm})$ of the A dye wavelength. Theoretically, adding $25 \%$ tannins of the B dye has led to the increasing quantity of chromophores and auxochrome in the AB1 dye. However, what should be noted is that the increase in tannin levels in $\mathrm{AB}$ dye will occur along with a decrease in brazilein levels and based on the results of the analysis it is suspected that there is a close relationship between the molecular size and the success of the fiber in binding dye molecules. The larger the size of the dye molecule is predicted to increase the barriers to fabric fibers to maximize the binding of the dye molecules. As shown in Fig. 2 (a), the molecular structure of brazilein has 2 types of chromophores 
$(\mathrm{C}=\mathrm{C}$ and $\mathrm{C}=\mathrm{O})$ and 2 types of auxochrome, ie $-\mathrm{OH}$ and $\mathrm{C}-\mathrm{O}$. Meanwhile, in Fig. 2 (b) it appears that although it has the same chromophore and auxochrome properties, the tannin molecular structure exhibits the higher quantity of the corresponding chromophores and auxochrome. The quantity of chromophores and auxochromes increases with increasing tannin levels to $50 \%$ and $75 \%$, as found in $\mathrm{AB} 2$ and $\mathrm{AB} 3$ dyes, respectively. The increase in the number of chromophores and auxochromes is predicted to be capable of inducing an increase in the number of electronic transitions, especially those involving the non-bonding orbital $(\mathrm{n}) \rightarrow$ phi antibonding $\left(\pi^{*}\right)$ and $\mathrm{n} \rightarrow$ sigma anti-bonding $\left(\sigma^{*}\right)$, which leads to a shift maximum wavelength and shades of color that appear. However, the higher effect of space difficulties that arise along with the increase in tannin content, which reaches its peak in the composition of the AB2 dye has triggered conditions where the bond formed between the fabric fibers and dyes molecules becomes minimum to produce a brighter color accompanied by lower redness $\left(\mathrm{a}^{*}\right)$ and yellowness $\left(b^{*}\right)$. The opposite phenomenon was detected when tannins dominated the AB3 dye extract. Increased tannins accompanied by decreased levels of brazilein appear to produce brighter shades, but with increasing levels of redness and yellowish. Thus, it can be reported that comparable levels of brazilein and tannins in the AB dye extract will produce a mutually nullifying effect. Slightly different from the conditions caused by the addition of tannins from Cocos nucifera extract, the addition of tannins from the Leucaena leucocephala extract, as seen in the AC1-AC3 dye composition, shows a lower magnification $(0.02 \mathrm{~nm})$ shift of the A dye wavelength. The condition is predicted to be triggered by mimosine pigment, which produces a complementary effect with tannins in the dye. This complementary effect is getting stronger because of the smaller molecular size of mimosine, which reduces the effect of space difficulties, which can inhibit the binding of dye molecules by fabric fibers. The presence of mimosine, with the molecular structure as shown in Fig. 2 (c), in AC1-AC3 extract has enriched the auxochrome variety of AC1-AC3 dyes, wherein the molecular structure of mimosine has N-H chromophores absent in $\mathrm{AB} 1-\mathrm{AB} 3$ dyes. This is the cause of the difference in bathochromic shifts that occur in AC1-AC3 dyes when compared to AB1-AB3 dyes. The condition also shows that in addition to increasing orbital quantities, the presence of mimosine has enriched the number of chromophores and the quantity and variety of auxochromes involved in the electronic transition of AC1-AC3 dyes when adsorbing light energy. These conditions make mimosine as one inducer of a larger bathochromic shift in AC1-AC3 dyes. This condition is following the color look of the extract is getting closer to the typical brown tannin.

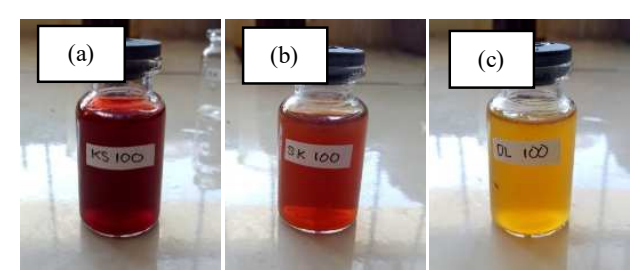

Fig. 1 Scheme of (a) Sappanwood bark; (b) Cocos nucifera fiber; (c) Leucaena leucocephala extract
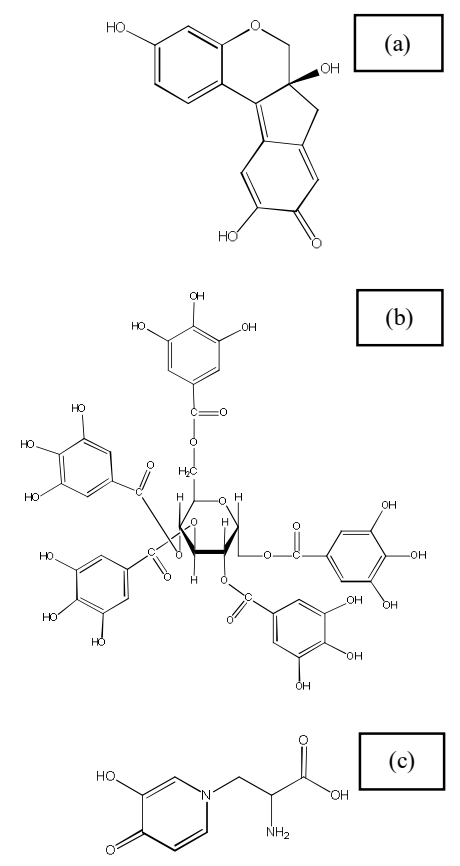

Fig. 2 Scheme of (a) brazilein; (b) tannin; (c) mimosine molecular structure

\section{B. UV-Visible Spectra}

The UV-Vis spectrum of Sappanwood bark (A) dye extract showed $\lambda \max$ at $538.57 \mathrm{~nm}$. These results confirm the presence of brazilein pigment in the Sappanwood bark extract. These results correspond to $\lambda$ max data of brazilein flavonoids at $540 \mathrm{~nm}$ reported by the ref. [28]. Meanwhile, the UV-Vis spectrum analysis results of Cocus Nucifera fiber and Leucaena leucocephala leaf extract showed the maximum absorption at $384.41 \mathrm{~nm}$ and $417.84 \mathrm{~nm}$. The difference in maximum wavelength between Cocus Nucifera fiber and Leucaena leucocephala leaf extract has strengthened the prediction of the presence of mimosine pigment as a complement of tannin in $\mathrm{C}$ dye extract. Fig. 3 shows the UV$\mathrm{Vis}$ spectra of the $\mathrm{A}, \mathrm{B}, \mathrm{C}, \mathrm{AB} 1-\mathrm{AB} 3$, and $\mathrm{AC} 1-\mathrm{AC} 3$ dye extracts. 


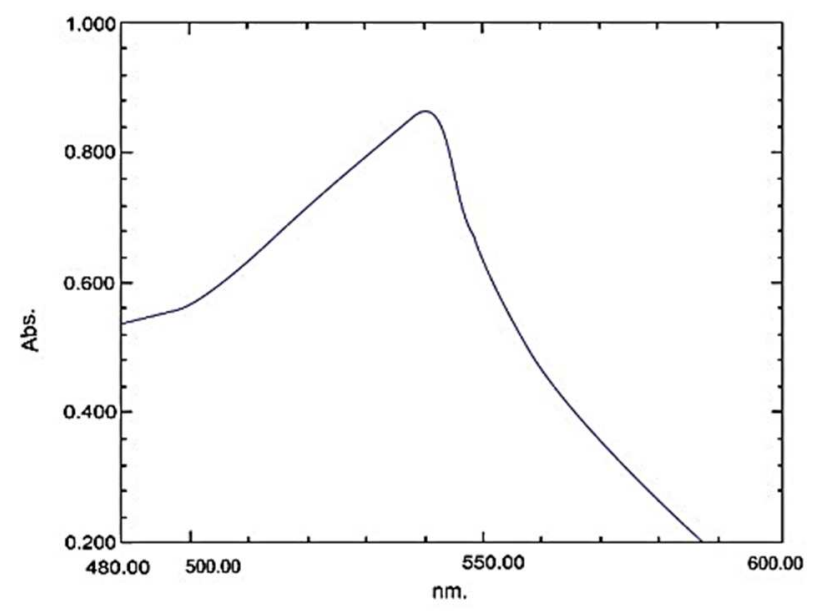

A

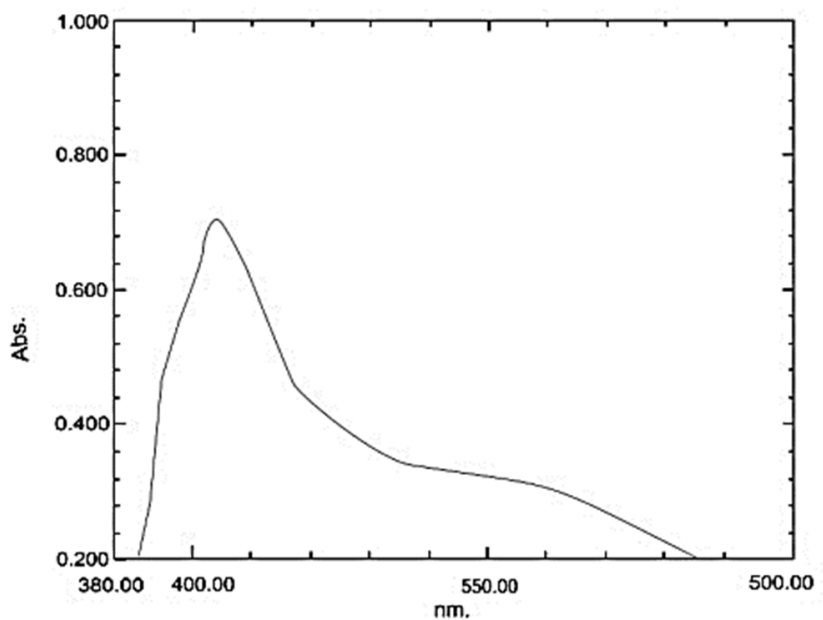

C

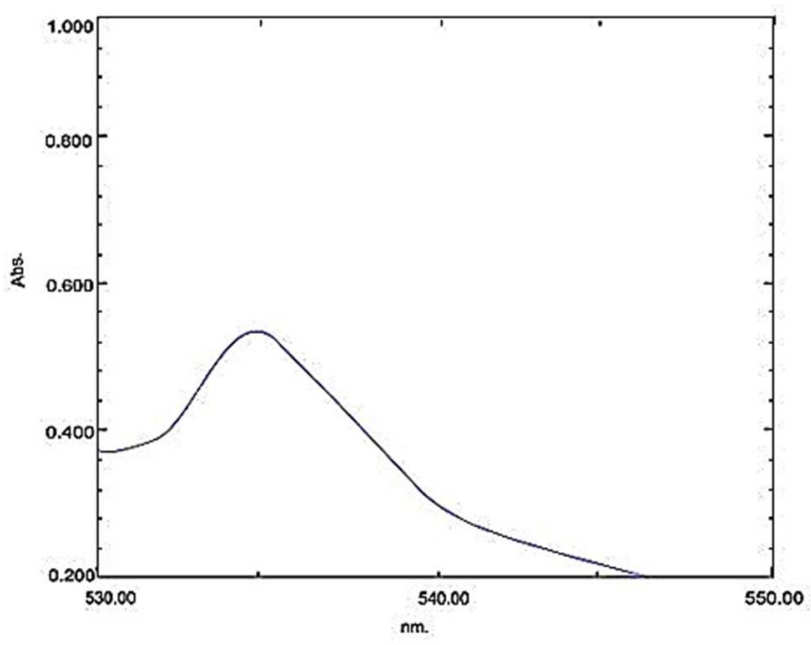

AB2

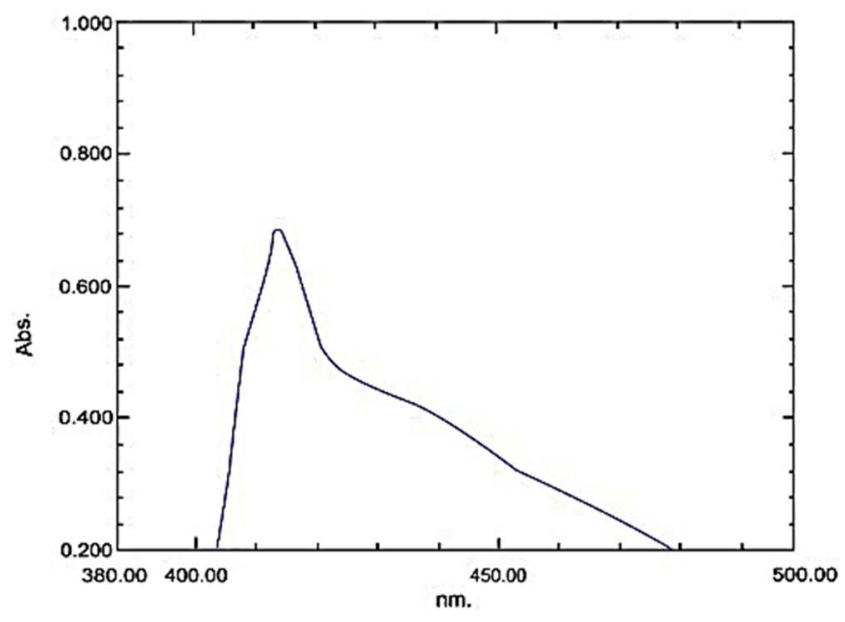

B

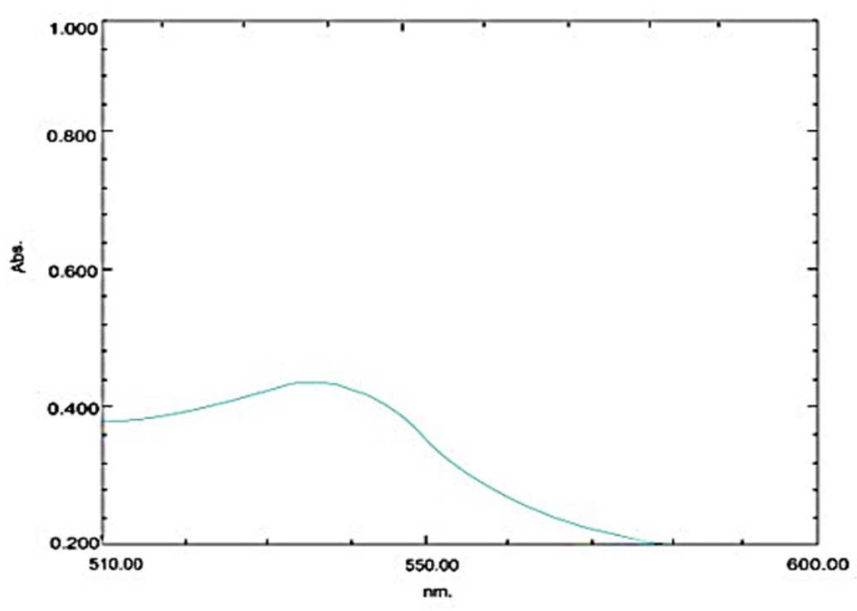

AB1

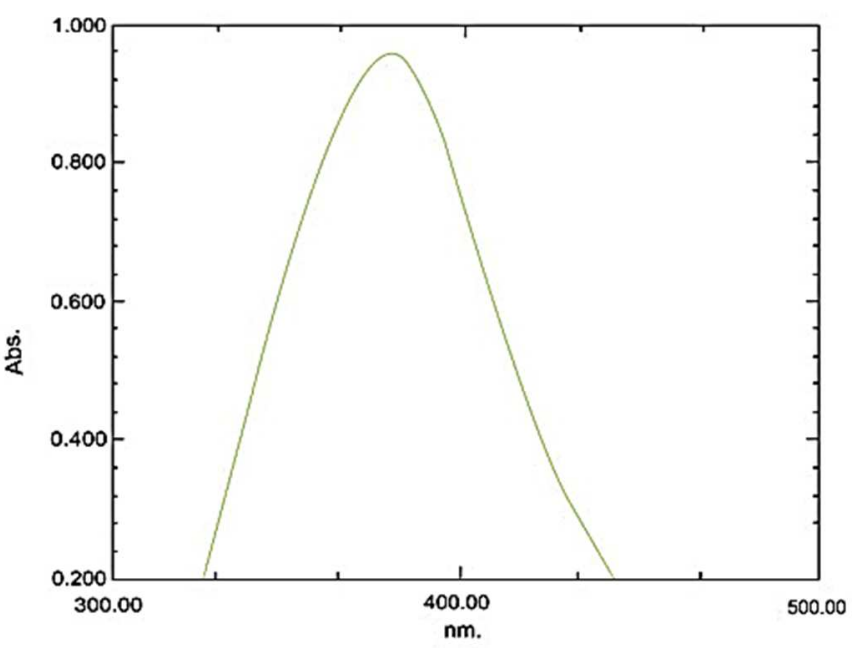

AB3 

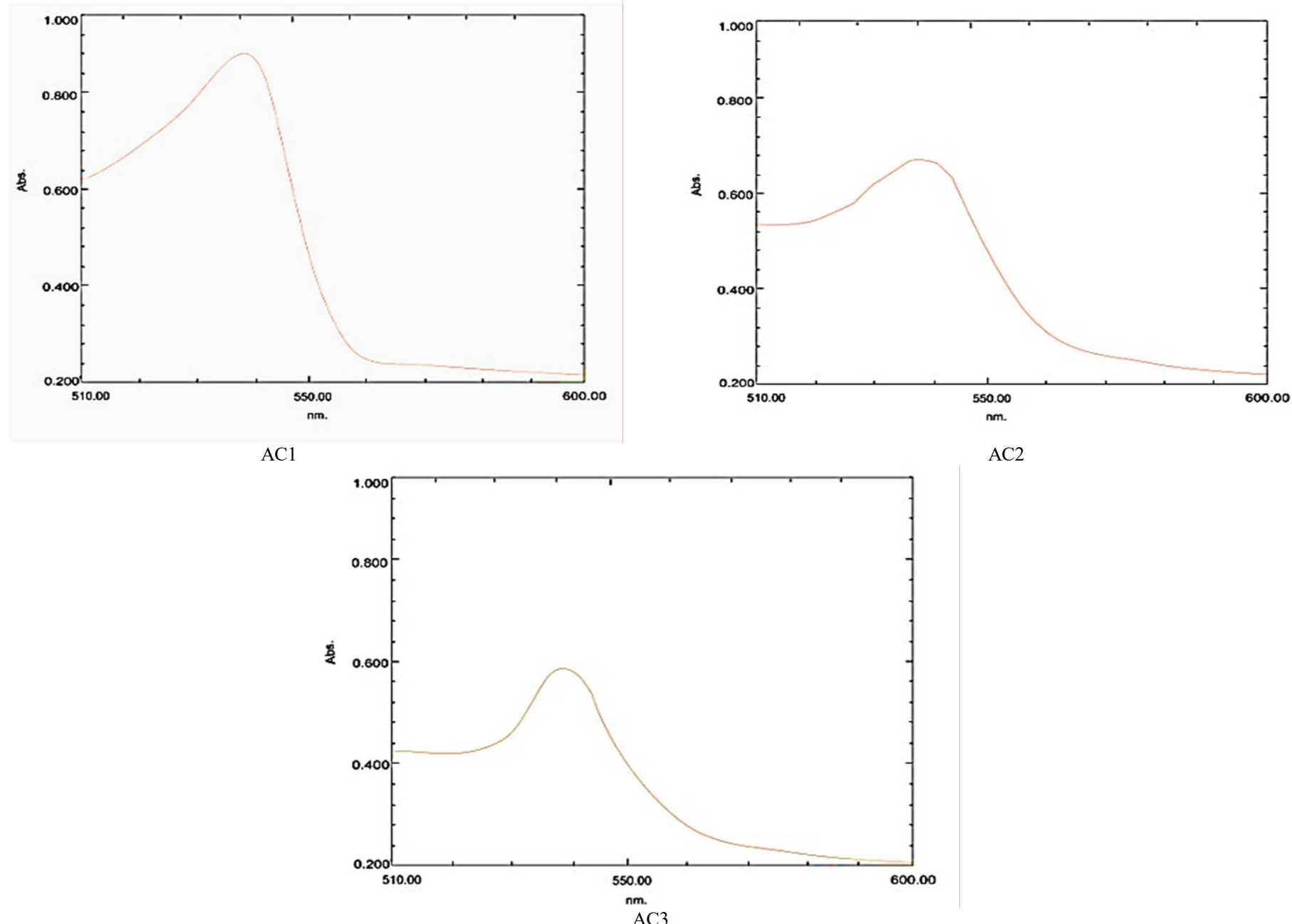

Fig. 3 UV-Visible spectra of dyes

Table 3 shows the colorimetric parameters of different compositions of dyes extract. The colorimetric analysis results showed that elevated levels of tannin pigment from Cocos nucifera fiber extract on AB1-AB3 dyes had resulted in a decrease in the brightness value from 47.34 in A dye, being respectively of 41.35 in $\mathrm{AB} 1$. It is closely related to the bathochromic events or maximum absorption shifts to higher wavelength regions triggered by an increase in the number of chromophores and auxochrome occurring as a result of tannin pigment added from Cocus nucifera to then synergize with brazilein pigment from Sappanwood bark extract. The same trigger has induced an increase in redness and yellowness value along with an increase in tannin content from Cocus nucifera fiber extract into Sappanwood bark extract. In general, almost the same phenomenon is detected in AB3 dyeing results. However, balanced levels of brazilein and tannin pigments in $\mathrm{AB} 2$ dyes have given rise to a mutually nullifying effect that minimizes the number of bonds between fabric fibers with both pigments, which increases the color brightness accompanied by a decrease in redness and yellowness compared to the colors produced by $\mathrm{AB} 1$ and $\mathrm{AB} 3$ dyes or when one of the pigments dominates. In detail, the results of dyeing using $\mathrm{AB} 2$ dye have brightness 49.95 with the $a^{*}$ and $b^{*}$ notation values of 24.80 and 9.22 , which are $9.90 \%$ and $29.18 \%$ lower compared to the $a^{*}$ and $b^{*}$ color notation values produced by $\mathrm{AB} 1$ dyes; and $20.89 \%$ and $54.56 \%$ lower than $\mathrm{AB} 3$ dyes.

TABLE III

COLORIMETRIC PARAMETER OF DIFFERENT DYES COMPOSITIONS

\begin{tabular}{lcccc}
\hline & \multicolumn{4}{c}{ CieLab Coordinate } \\
\cline { 2 - 5 } & $\mathrm{L}^{*}$ & $\mathrm{a}^{*}$ & $\mathrm{~b}^{*}$ & $\mathrm{dE}$ *ab \\
\hline $\mathrm{A}$ & 47.34 & 19.02 & 6.97 & 56.25 \\
$\mathrm{~B}$ & 78.42 & 12.16 & 28.64 & 37.68 \\
$\mathrm{C}$ & 69.00 & 17.40 & 37.20 & 51.27 \\
$\mathrm{AB} 1$ & 41.35 & 27.26 & 11.91 & 65.61 \\
$\mathrm{AB} 2$ & 49.95 & 24.80 & 9.22 & 56.46 \\
$\mathrm{AB} 3$ & 52.57 & 29.98 & 14.25 & 57.75 \\
$\mathrm{AC} 1$ & 52.80 & 23.67 & 6.22 & 53.03 \\
$\mathrm{AC} 2$ & 64.64 & 29.68 & 16.69 & 48.98 \\
$\mathrm{AC} 3$ & 64.06 & 27.74 & 15.64 & 47.89 \\
\hline
\end{tabular}

Note : L* : brightness; $a^{*}:($ red $=+v e$, green $=-v e) ; b^{*}($ yellow $=+v e$, blue $=-\mathrm{ve})$

The corresponding conditions were detected in the analysis results of the $\mathrm{AC} 1-\mathrm{AC} 3$ colorimetric parameters. Brightness value ( $\left.\mathrm{L}^{*}\right)$ of $\mathrm{AC} 1-\mathrm{AC} 3$ dye showed an increasing trend along with elevated levels of tannin from Leucaena leucocephala leaf extract added to Sappanwood bark extract. However, as described in the preceding section, the presence of mimosine pigment as a tannin complement in Leucaena leucocephala leaf extract has triggered an increase in the number of chromophores as well as the quantity and diversity of auxochrome which is bonded to the fabric fibers and induces 
less significant maximum wavelength shifts in AC1-AC3. However, in contrast to the dyeing phenomenon by $\mathrm{AB} 2$, the results of dyeing using AC2 dyes produce an increase in brightness, accompanied by an increase in the $\mathrm{a}^{*}$ and $\mathrm{b}^{*}$ notation values compared to $\mathrm{AC} 1$. The decrease in brightness, although not significant, together with a decrease in the notation values of $a^{*}$ and $b^{*}$ was only detected after an increase in tannin and mimosine levels in the dye reached the maximum (AC3). The decrease in CieLab coordinate in this condition is thought to be closely related to the minimum presence of brazilein pigment in the AC3 dyes, which has led to a decrease in the resulting redness and yellowness color. More specifically, this is reinforced by the results of the analysis showing the more dominant level of redness of AB3 and the yellowness level of AC3 dyes.

\section{Fourier Transform Infra-Red Spectroscopy}

To confirm the presence of red-pink chromophore from brazilein, the FT-IR spectrum showed adsorption at wavenumbers $1635.71 \mathrm{~cm}^{-1}$ from $\mathrm{C}=\mathrm{C}$ aromatic stretching (Fig. 4 and Table 4). Based on these adsorptions, the FT-IR analysis confirmed the presence of chromophores $\mathrm{C}=\mathrm{C}$. Meanwhile, the presence of auxochromes - $\mathrm{OH}$ in the brazilein structure has been confirmed by the appearance of respective absorption at wavenumbers $3265.86 \mathrm{~cm}^{-1}$. The absorption details arising from the analysis of FT-IR A dyes are shown in Figs. 4 and Table 4.

In addition to brazilein, FT-IR analysis was also applied to confirm the presence of reddish-brown chromophore from tannins, both in B and C dyes. Specifically for C dye, the FTIR analysis has been very useful for confirming the predicted presence of mimosine pigments as tannins complement the extracts. The FT-IR result of B dye shows that the absorption does not differ significantly from A dye. The absorption at wavenumber $1636.05 \mathrm{~cm}^{-1}$ of $\mathrm{C}=\mathrm{C}$ aromatic stretching has confirmed the presence of heterocyclic compounds with the

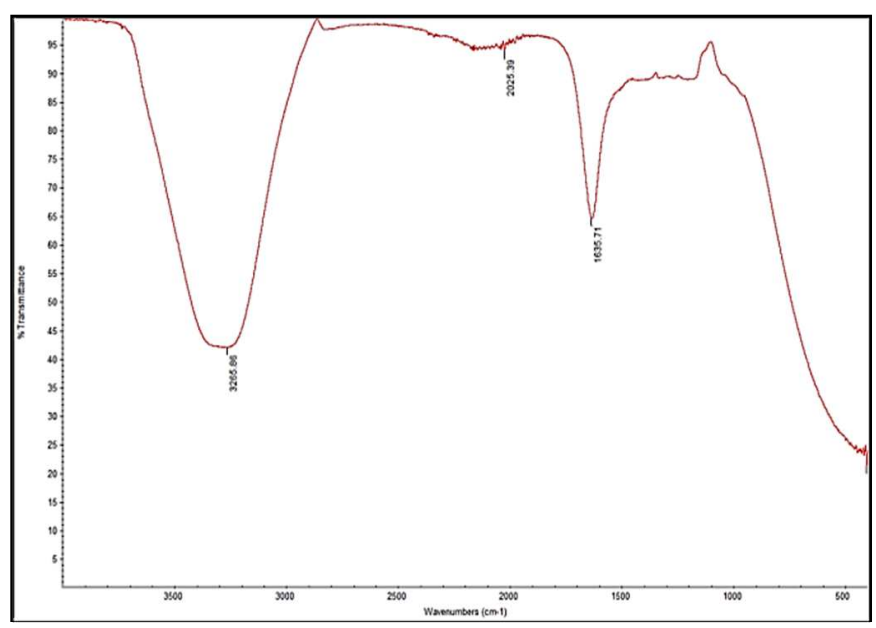

A aromatic ring of the tannin molecule. These of FT-IR FTIR result has also confirmed the presence of $\mathrm{C}=\mathrm{C}$ chromophores of tannin molecules. Meanwhile, the emergence of -OH and $\mathrm{CO}$ auxochromes in tannin molecular structure has been confirmed by peak incidence at wavenumbers $3265.04 \mathrm{~cm}^{-1}$ and $2154.48 \mathrm{~cm}^{-1}$. The only characteristic differentiation between brazilein and tannin is a peak that appears at wavenumber $2154.48 \mathrm{~cm}^{-1}$ which indicates the presence of C$\mathrm{O}$ functional groups typical of the ester group.

Especially for the results of $\mathrm{C}$ dye analysis, the appearance of the peak in wave number $1636.19 \mathrm{~cm}^{-1}$ indicates the presence of $\mathrm{C}=\mathrm{C}$ chromophore and $\mathrm{N}-\mathrm{H}$ auxochrome. This result further strengthens the results of the DRUV and UVVis spectrophotometers analysis which show a lower bathochromic shift to the maximum wavelength of the A dye. The condition has triggered the appearance of $\mathrm{C}$ dye that has lower brightness as well as higher redness and yellowness values than the $\mathrm{B}$ dye. This is closely related to the similarity of the chromophores and auxochromes quantity between $\mathrm{A}$ dye and $\mathrm{C}$ dye compared to that of $\mathrm{B}$ dye. This has induced the similarity of the electronic transitions occurring in A dye and $\mathrm{C}$ dye as compared to the $\mathrm{B}$ dye when adsorbing light.

TABLE IV

FT-IR VIBRATION ASSIGNMENT OF DYES

\begin{tabular}{lccccc}
\hline \begin{tabular}{c} 
Vibration \\
assignmen \\
\multicolumn{1}{c}{$\mathbf{t}$}
\end{tabular} & $\mathbf{A}$ & $\mathbf{B}$ & $\mathbf{C}$ & $\mathbf{A B 1}$ & $\mathbf{A C 1}$ \\
\cline { 2 - 6 } & & & & & \\
\hline$-\mathrm{OH}$ & 3265.8 & 3265.0 & 3279.5 & 3269.2 & 3281.7 \\
& 6 & 4 & 7 & 0 & 3 \\
$\mathrm{C}=\mathrm{C}$ & 1635.7 & 1636.0 & 1636.1 & 1633.2 & 1635.7 \\
stretch, & 1 & 5 & 9 & 7 & 2 \\
aromatic & & & & & \\
$\mathrm{N}-\mathrm{H}\left(1^{\circ}\right.$ & - & - & 1636.1 & - & 1635.7 \\
amine) & & & 9 & & 2 \\
$\mathrm{C}-\mathrm{O}$ esther & - & 2154.4 & 2129.9 & 2147.8 & 2162.9 \\
& & 8 & 7 & 8 & 5 \\
\hline
\end{tabular}

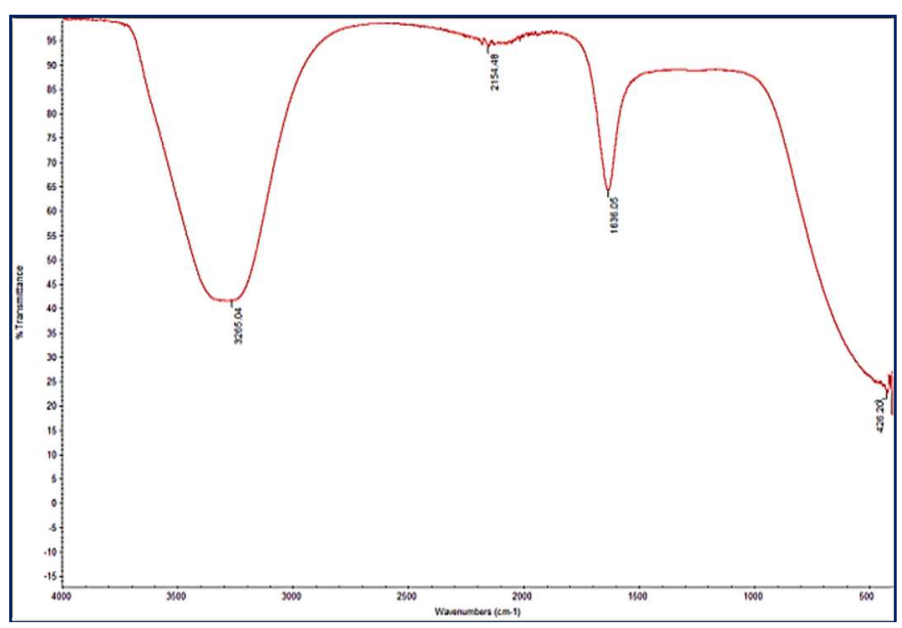

B 


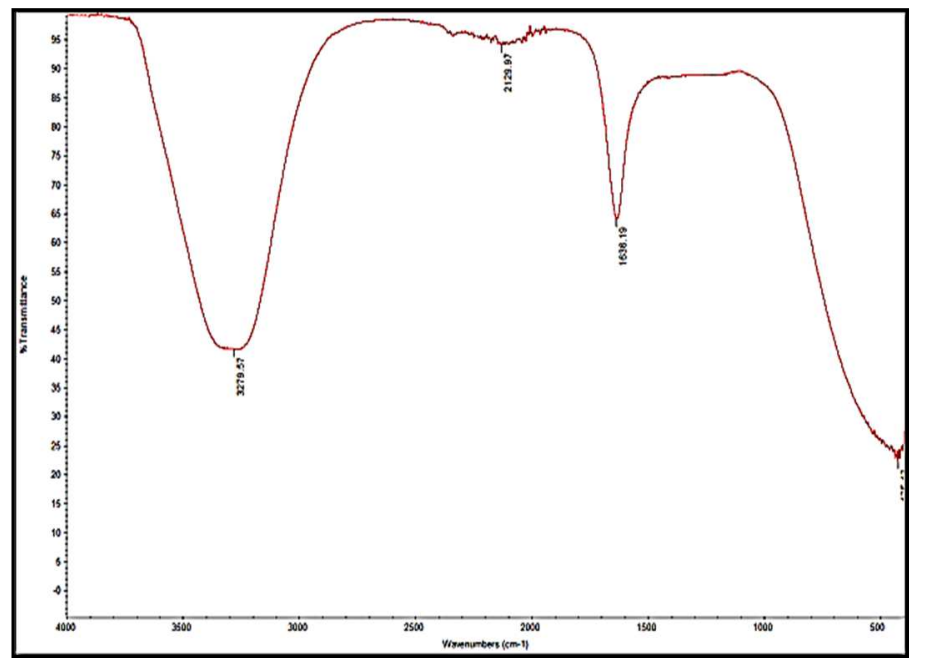

C

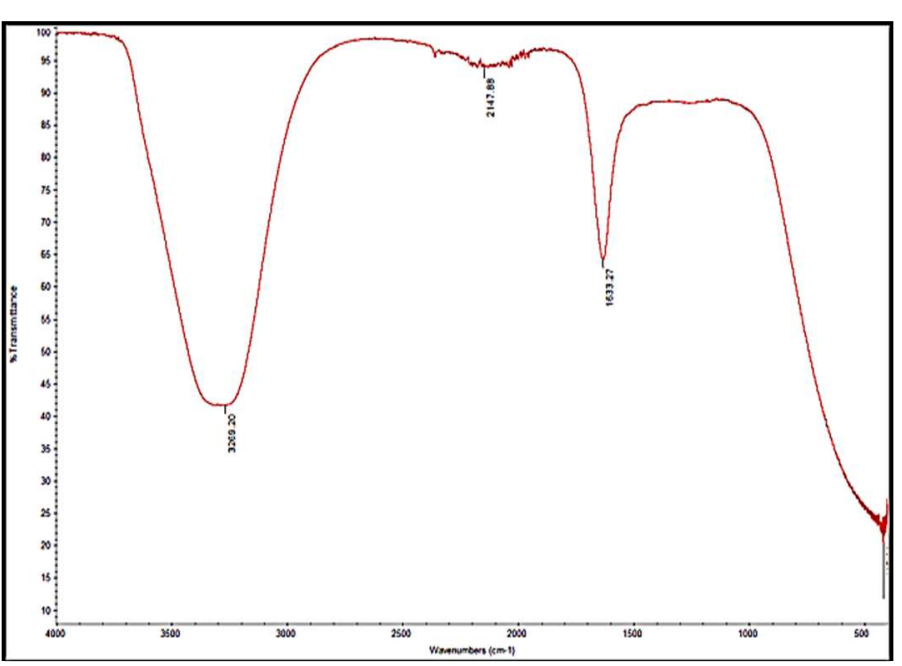

AB2

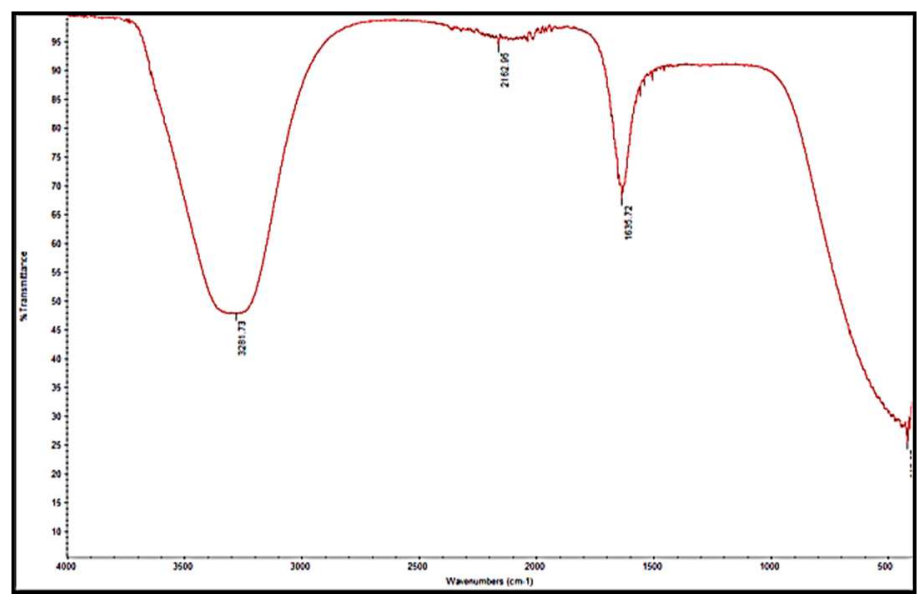

$\mathrm{AC} 2$

Fig. 4 FT-IR spectra of dyes

\section{Diffuse Reflectance Ultraviolet (DRUV)}

The effect of the dye composition on the variety of shades, strength, and fastness was studied by varying the $\mathrm{B}$ and $\mathrm{C}$ dye as the mixture of the A dye which became the main dye in this study (with a ratio of $75 / 25 ; 50 / 50 ; 25 / 75$ ) and by using 3 types of fixer compounds to enrich the original shades of the Sappanwood bark extract. Fig. 5 and Fig. 6 show the shades and reflectance values of the colors produced by each color combination and type of fixer. In general, higher reflection percentages will result in higher color intensity.

Implementation of dyeing ending with the fixation process using three different fixer compounds proved to have enriched the shades produced by the A dye. The physical appearance of the dyeing results in Fig. 5 shows the appearance of dark brown for fixation with iron (II) sulfate and red for both other fixation, alum, and calcium oxide. The combination of the presence of specific chromophores and auxochromes from dyes and fixers used is predicted to induce the appearance of specific colors from the use of each fixer. Fig. 7 appear different types of chromophores in the three fixer types of compounds used. In fixer iron (II), sulfate and alum appear to have $\mathrm{S}=\mathrm{O}$ chromophore and $\mathrm{S}-\mathrm{O}$ auxochrome, whereas there is only 1 type of chromophore in the calcium oxide fixer, ie $\mathrm{Ca}=\mathrm{O}$. The only difference between fixer iron (II) sulfate and alum is in the higher quantity of chromophore and auxochromes in the alum fixer.

Different patterns of influence emerged from the application of three different types of fixers to dyeing using $B$ and $\mathrm{C}$ dyes. The dyeing results using $\mathrm{B}$ dye indicate the appearance of blackish brown, light brown, and dark brown resulting from the use of fixers iron (II) sulfate, alum, and calcium oxide. Similar to the results, dyeing using $\mathrm{C}$ dye denotes the appearance of gray, light yellow, and yellow in color resulting from the use of fixers iron (II) sulfate, alum, and calcium oxide. Despite having the same pigment content, $\mathrm{B}$ and $\mathrm{C}$ dyes show the appearance of different shades, though not significantly. This is closely related to the presence of mimosine pigment as a differentiator of pigment content in $\mathrm{B}$ and $\mathrm{C}$ dyes. Besides, the presence of mimosine pigments in addition to tannins in $\mathrm{C}$ dye has induced the appearance of similar colors with higher brightness and yellowness and lower redness values in $\mathrm{C}$ dye compared with $\mathrm{B}$ dye. This finding is relevant to the results of the colorimetric parameters and DRUV analysis shown in Table 5 - Table 7. More specifically, the DRUV data have shown a lower reflectance percentage of the shades produced by the $\mathrm{C}$ dye, both terminated by fixation using iron (II) sulfate, alum, and calcium oxide. 


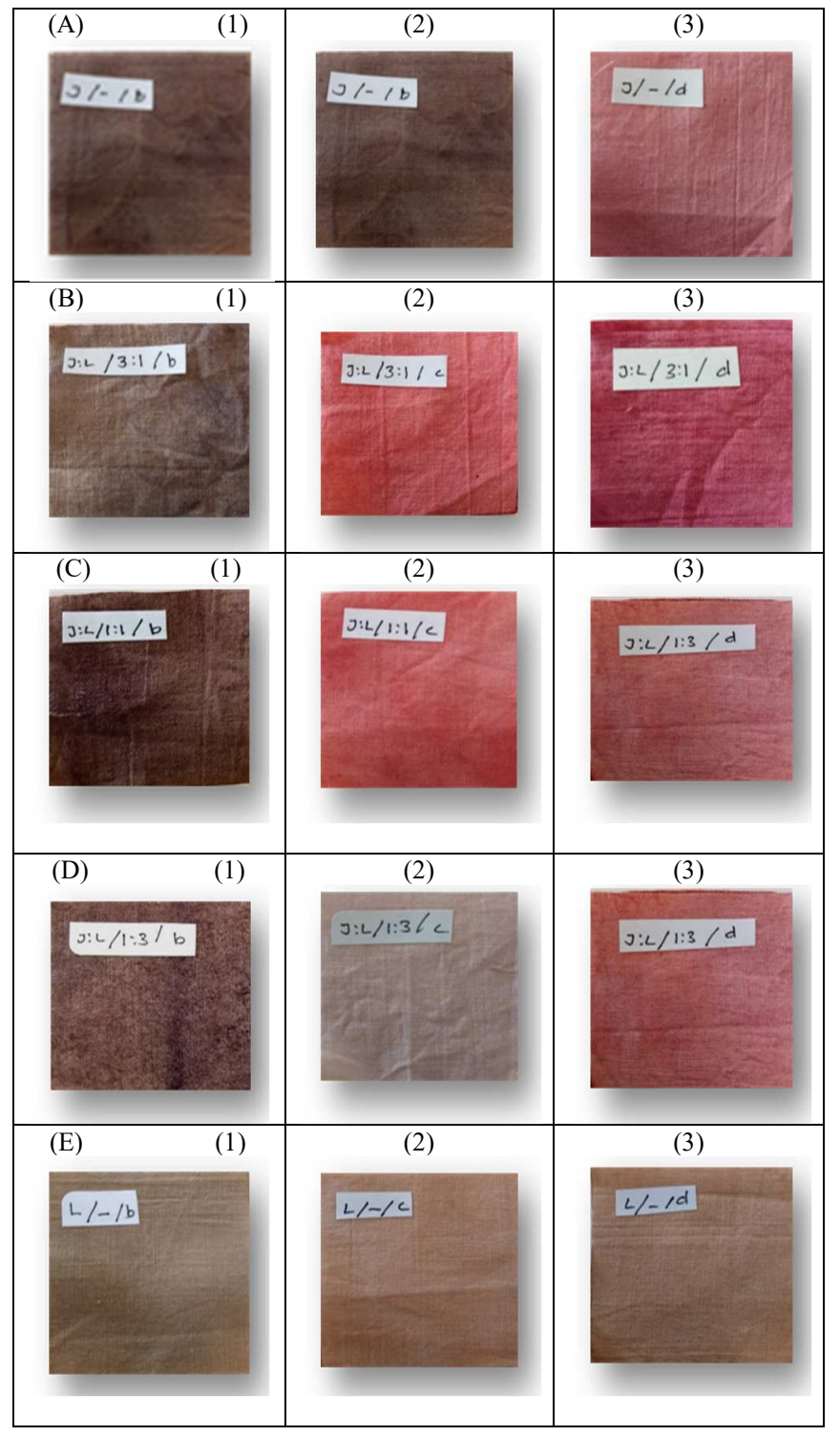

Fig. 5 Physical appearance of : (a) A; (b) AB1; (c) AB2; (d) AB3; (e) B dyes with fixer : (1) iron (II) sulfate; (2) alum; and (3) calcium oxide

When adding more $\mathrm{B}$ dye to $\mathrm{A}$ dye, each cotton fiber sample gives shades of light brown, light red, and pink colors that fade respectively on the dyeing result fixed with an iron (II) sulfate, alum, and calcium oxide fixer, as shown in Fig. 5. This condition indicates that the addition of $\mathrm{B}$ dye with various compositions has tended to enrich the shades of $\mathrm{A}$ dyes produced through the creation of shades gradations predicted due to the interaction competition between brazilein pigments from $\mathrm{A}$ dye and tannin pigments from $\mathrm{B}$ dye. Increases in B dyes levels in the dye composition will produce shades with a lower brightness for dyeing, which ends with fixation using iron (II) sulfate, while the application of alum and calcium oxide fixers results in increased brightness shades. This finding is relevant to the results of the colorimetric parameters analysis shown in Table 5 and the color reflectance shown in Table 7. Overall, increases in the $\mathrm{B}$ dye amount added have been shown to increase the percentage of reflectance from the dye. This condition shows a decrease in color intensity in dyeing with increasing tannin levels.

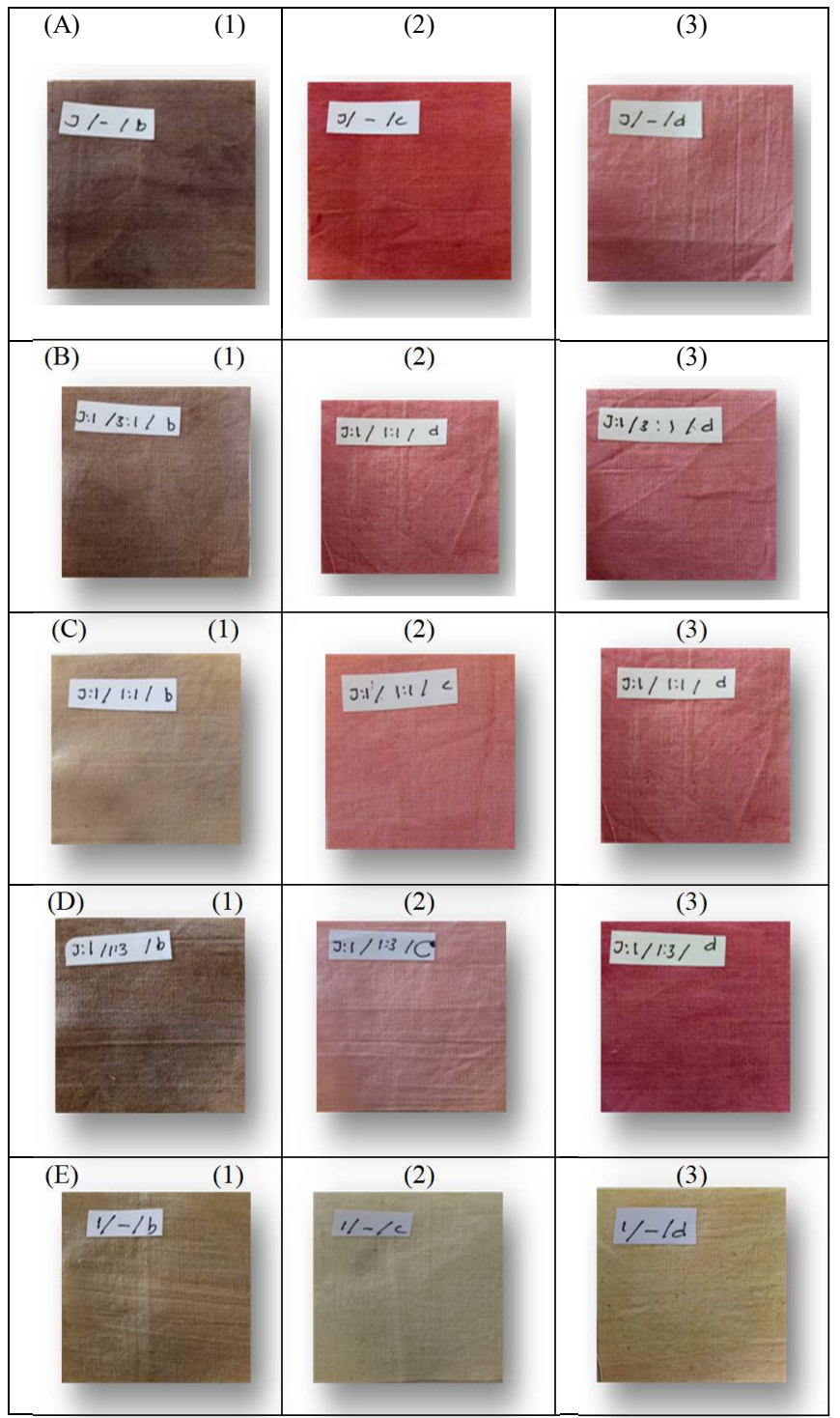

Fig. 6 Physical Appearance of : (a) A; (b) AC1; (c) AC2; (d) AC3; (e) C Dyes with Fixer: (1) iron (II) sulfate; (2) alum; and (3) calcium oxide

Similar to the results obtained from the combination of A and $\mathrm{B}$ dyes, the result of an $\mathrm{A}$ and $\mathrm{C}$ dyes combination has triggered the appearance of the shades of blackish brown, dark pink, and light pink that fade respectively on the dyeing result fixed with an iron (II) sulfate, alum, and calcium oxide fixer, as shown in Fig. 6. This condition indicates that the addition of $\mathrm{C}$ dye with various compositions has tended to enrich the shades of A dyes, which produce through the creation of shades gradations predicted due to the interaction competition between brazilein pigments from A dye and combination of tannin and mimosine pigments from $\mathrm{C}$ dye. Increased levels of $\mathrm{C}$ dye used in dyeing give varying results in CieLab coordinate. On the results of dyeing using $\mathrm{AC}$ which ends with fixation using iron (II) sulfate detected to give color shades increasing brightness, while the use of alum and calcium oxide fixers, each of which results in the emergence of color shades with stable and decreasing brightness. This finding is relevant to the results of the colorimetric parameters analysis shown in Table 5 and the color reflectance shown in Table 6. In general, increases in the $\mathrm{C}$ dye amount added have been shown to increase the percentage of reflectance from the 
dye. This condition shows a decrease in color intensity in dyeing with increasing tannin and mimosine levels.

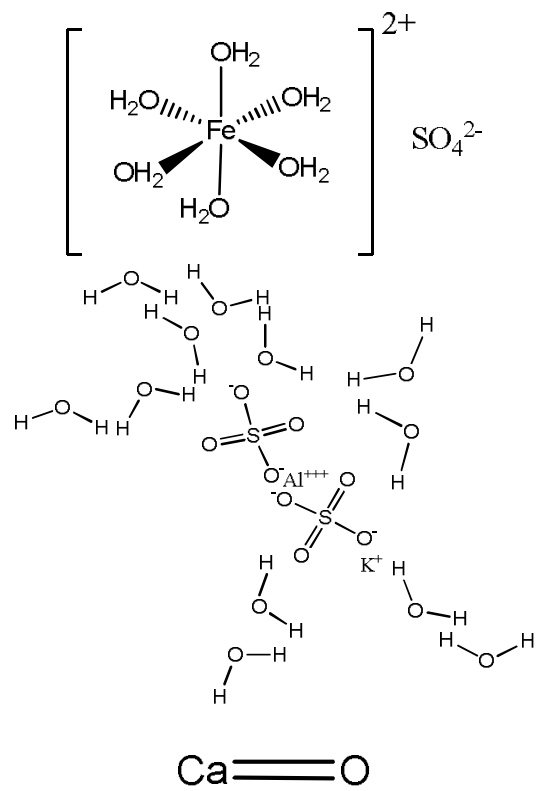

Fig. 7 The molecular structure of the fixer: (a) iron (II) sulfate; (b) alum; and (c) calcium oxide

TABLE V

A COLORIMETRIC PARAMETER OF DIFFERENT DYES COMPOSITIONS AND FIXER

\begin{tabular}{|c|c|c|c|c|}
\hline & \multicolumn{4}{|c|}{ CieLab Coordinate } \\
\hline & $\mathrm{L}^{*}$ & $\mathrm{a}^{*}$ & $\mathrm{~b}^{*}$ & $\mathrm{dE} * \mathrm{ab}$ \\
\hline A - Iron (II) sulfate & 53.00 & 5.92 & 4.80 & 53.55 \\
\hline A - Alum & 54.49 & 26.40 & 12.70 & 61.87 \\
\hline A - Calcium oxide & 67.49 & 22.43 & 12.64 & 61.87 \\
\hline B - Iron (II) sulfate & 62.76 & 6.16 & 14.90 & 64.80 \\
\hline B - Alum & 74.99 & 14.50 & 24.50 & 80.21 \\
\hline B - Calcium oxide & 85.29 & 9.94 & 22.47 & 88.76 \\
\hline C - Iron (II) sulfate & 68.76 & 5.90 & 19.13 & 72.62 \\
\hline $\mathrm{C}-$ Alum & 83.84 & 1.18 & 31.80 & 89.67 \\
\hline $\mathrm{C}-$ Calcium oxide & 81.09 & 2.62 & 41.40 & 91.08 \\
\hline $\begin{array}{l}\text { AB1 - Iron (II) } \\
\text { sulfate }\end{array}$ & 43.08 & 6.79 & 7.13 & 44.19 \\
\hline AB1 - Alum & 52.74 & 39.91 & 20.26 & 69.18 \\
\hline $\begin{array}{l}\text { AB1 - Calcium } \\
\text { oxide }\end{array}$ & 44.32 & 29.90 & 9.09 & 54.32 \\
\hline $\begin{array}{l}\text { AB2 - Iron (II) } \\
\text { sulfate }\end{array}$ & 38.19 & 7.09 & 9.25 & 39.93 \\
\hline AB2 - Alum & 56.98 & 36.36 & 21.03 & 70.79 \\
\hline $\begin{array}{l}\mathrm{AB} 2-\text { Calcium } \\
\text { oxide }\end{array}$ & 53.51 & 23.26 & 9.92 & 59.20 \\
\hline $\begin{array}{l}\text { AB3 - Iron (II) } \\
\text { sulfate }\end{array}$ & 31.28 & 7.81 & 8.52 & 33.35 \\
\hline AB3 - Alum & 87.90 & 12.41 & 12.20 & 89.60 \\
\hline $\begin{array}{l}\text { AB3 - Calcium } \\
\text { oxide }\end{array}$ & 60.65 & 28.57 & 15.35 & 68.78 \\
\hline $\begin{array}{l}\text { AC1 - Iron (II) } \\
\text { sulfate }\end{array}$ & 56.00 & 6.83 & 11.23 & 57.52 \\
\hline AC1 - Alum & 67.58 & 32.23 & 17.27 & 76.83 \\
\hline $\begin{array}{l}\mathrm{AC} 1-\text { Calcium } \\
\text { oxide }\end{array}$ & 67.59 & 22.11 & 11.00 & 71.95 \\
\hline $\begin{array}{l}\text { AC2 - Iron (II) } \\
\text { sulfate }\end{array}$ & 70.97 & 6.08 & 14.39 & 72.67 \\
\hline AC2 - Alum & 67.56 & 34.75 & 20.60 & 78.71 \\
\hline $\begin{array}{l}\text { AC2 - Calcium } \\
\text { oxide }\end{array}$ & 65.46 & 23.08 & 10.17 & 70.16 \\
\hline $\begin{array}{l}\text { AC3 - Iron (II) } \\
\text { sulfate }\end{array}$ & 49.90 & 5.74 & 7.14 & 50.74 \\
\hline
\end{tabular}

\begin{tabular}{|c|c|c|c|c|}
\hline AC3 - Alum & 67.32 & 33.03 & 29.48 & 80.57 \\
\hline $\begin{array}{l}\text { AC3 - Calcium } \\
\text { oxide }\end{array}$ & 42.09 & 29.26 & 8.16 & 51.91 \\
\hline
\end{tabular}

TABLE VI

DRUV OF THE DYES WITH DIFFERENT COMPOSITIONS

\begin{tabular}{lcc}
\hline & Reflectant (\%) & Intensity (\%) \\
\hline A & 8.31 & 94.34 \\
B & 42.77 & 59.88 \\
C & 26.29 & 76.36 \\
AB1 & 11.51 & 91.14 \\
AB2 & 15.94 & 86.71 \\
AB3 & 12.67 & 89.98 \\
AC1 & 28.94 & 73.71 \\
AC2 & 28.11 & 74.54 \\
AC3 & 37.17 & 65.48 \\
\hline
\end{tabular}

TABLE VII

THE REFLECTANCE OF Dyes With DifFERENT COMPOSITION AND FIXER TYPE

\begin{tabular}{lcc}
\hline & Reflectant (\%) & Intensity (\%) \\
\hline A - Iron (II) sulfate & 23.36 & 79.29 \\
A - Alum & 14.94 & 87.71 \\
A - Calcium oxide & 21.76 & 80.89 \\
B - Iron (II) sulfate & 18.01 & 84.64 \\
B - Alum & 36.47 & 66.18 \\
B - Calcium oxide & 33.81 & 68.84 \\
C - Iron (II) sulfate & 16.70 & 85.95 \\
C - Alum & 30.89 & 71.76 \\
C - Calcium oxide & 23.86 & 78.79 \\
AB1 - Iron (II) sulfate & 10.15 & 92.50 \\
AB1 - Alum & 21.79 & 80.86 \\
AB1 - Calcium oxide & 17.77 & 84.88 \\
AB2 - Iron (II) sulfate & 28.13 & 74.52 \\
AB2 - Alum & 30.80 & 71.85 \\
AB2 - Calcium oxide & 31.41 & 71.24 \\
AB3 - Iron (II) sulfate & 23.69 & 78.96 \\
AB3 - Alum & 28.99 & 73.66 \\
AB3 - Calcium oxide & 49.10 & 53.55 \\
AC1 - Iron (II) sulfate & 18.49 & 84.16 \\
AC1 - Alum & 40.35 & 62.30 \\
AC1 - Calcium oxide & 27.09 & 75.56 \\
AC2 - Iron (II) sulfate & 23.72 & 78.93 \\
AC2 - Alum & 24.57 & 78.08 \\
AC2 - Calcium oxide & 21.16 & 81.49 \\
AC3 - Iron (II) sulfat & 21.89 & 80.76 \\
AC3 - Alum & 30.52 & 72.13 \\
AC3 - Calcium oxide & 20.90 & 81.75 \\
\hline
\end{tabular}

\section{E. Staining Scale}

The wash fastness properties of the nine dyes compositions of the focus in this study are illustrated by the staining scale in Table 8(a)-(b). It appears that the original dyes, including $\mathrm{A}, \mathrm{B}$, and $\mathrm{C}$ dyes, each capable of inducing the appearance of specific shades with staining scale values of each are equal to 2-3 (less); 3 (enough), and 3 (enough). The wash fastness properties of the dyes are important to evaluate to determine the ability of each dye to maintain its existence in the mixture through competition with its companion dye in interacting with the alum mordant, which mediating the interaction between the cotton fibers and the dye.

Compared with $\mathrm{B}$ and $\mathrm{C}$ dyes, $\mathrm{A}$ dye has the lowest wash fastness. In the early stages of adding $B$ dye to A dye (AB1 dye), the dye staining scale value is constantly detected at the value/range 2-3 (less). The constant value of this staining 
scale continues to hold up to $50 \%$ of the B dye added to the mixture (AB2 dye). The increase in staining scale values begins to appear in the addition of $75 \%$ of the $\mathrm{B}$ dye into the mixture ( $\mathrm{AB} 3$ dye). By comparing the staining scale values of $\mathrm{A}$ and $\mathrm{B}$ dyes as the origin dyes of this combination, it can be seen that tannin pigment ( $\mathrm{B}$ dye) competitiveness is superior to that of brazilein pigment in A dye.

The pattern of color behavior appears on the dyeing results using a combination of $\mathrm{A}$ and $\mathrm{B}$ dyes, both of which then ends with fixation using iron (II) sulfate, alum, and calcium oxide. The appearance of shades is strongly influenced by the mutually supportive or mutually exclusive properties between the chromophores and the auxochromes, which are either owned by dyes or fixers. This is evidenced by the same pattern of similarity formed between the $\mathrm{AB} 1$ and $\mathrm{AB} 2$ dyes terminated by fixation using all three types of fixers used with the result of A dye with the same three fixer types. Similarly, the resultant dye behavior produced by the $\mathrm{AB} 3$ dye having similarities to the B dye produced from the same fixer. This finding is in line with the similarity of the three colorimetric parameters (brightness, redness, and yellowness) produced by $\mathrm{AB} 1$ and $\mathrm{AB} 2$ dyes with $\mathrm{A}$ dye and $\mathrm{AB} 3$ dye with $\mathrm{B}$ dye.

The evaluation result of the $\mathrm{C}$ dye addition to the $\mathrm{A}$ dye (AC dye) shows that when into the A dye is added a small amount of $\mathrm{C}$ dye ( $\mathrm{ACl}$ dye), the staining scale value of the dye is constantly detected at the value/range 3 (enough). However, in contrast to the behavior of the $\mathrm{AB}$ dye, the staining scale has increased with increasing $\mathrm{C}$ dyes added (up to $50 \%$ ) and has decreased when the $\mathrm{C}$ dyes added raise to $75 \%$ (AC3 dye). This condition is predicted to occur due to the presence of mimosine pigment as a tannin complement in the $\mathrm{C}$ dye. As has been explained previously, the presence of mimosine pigment, one of which has enriched the auxochrome variety, through the presence of the $-\mathrm{CN}$ and $\mathrm{NH}$ bonds. The presence of nitrogen atoms with high electronegativity will tend to strengthen the interaction with mordant alum and minimize the potential of staining scale decrease in dyeing results using this type of dye. This suggests a synergistic or mutually reinforcing effect between chromophores and auxochromes, both owned by brazilein as well as tannins and mimosine pigments. This finding is also in line with the physical appearance of $\mathrm{AC} 1, \mathrm{AC} 2$, and $\mathrm{AC} 3$ dyes, which still show similarities with the A dye through the emergence of typical gradations of brazilein pigment. This result is reinforced by the similarity of the brightness, redness, and yellowness values, as shown in Table 5, between the dye A with the $\mathrm{AC} 1, \mathrm{AC} 2$, and $\mathrm{AC} 3$ dyes.

The better behavior is shown by the wash fastness resulting from $\mathrm{AB}$ and $\mathrm{AC}$ dyes with iron (II) sulfate as fixers compounds. However, the opposite phenomenon can be observed from wash fastness, which decreases when dyeing ends with fixation using alum and calcium oxide. Thus, the use of three different fixers is not only influential on the shades variation and colorimetric parameters, but also the wash fastness. The wash fastness is influenced by the strength of interaction, either between fabric fibers with mordant alum, mordant alum with specific dye, or dye with each type of fixer used. However, if further investigated, the application of iron (II) sulfate fixer as soon as the dyeing process is completed is detected capable of producing the best wash fastness through the appearance of a specific shade with the highest staining scale value, ie 4 (good). To provide a more complete illustration of the interactions that occur in the dyeing process using Sappanwood bark, Cocus nucifera fiber, and Leucaena leucocephala leaf extract, in Fig. 8- Fig. 16 appears interaction between cotton fiber, mordant, pigment, and each type of fixer.

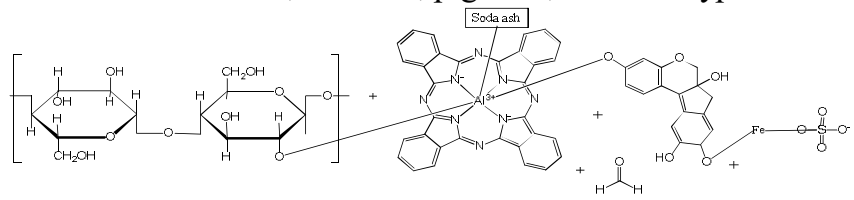

Fig. 8 The interaction of the dyeing process using brazilein pigment with iron (II) sulfate fixer

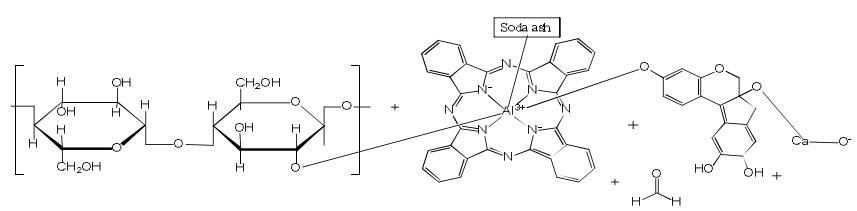

Fig. 9 The interaction of the dyeing process using brazilein pigment with alum fixer

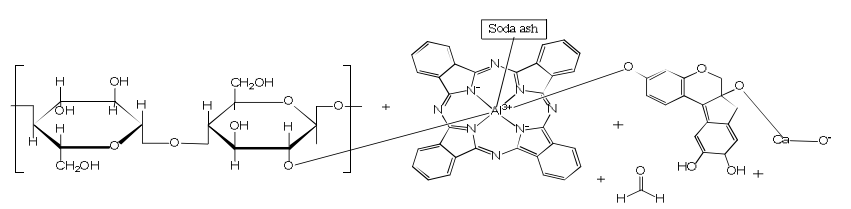

Fig. 10 The interaction of the dyeing process using brazilein pigment with calcium oxide fixer

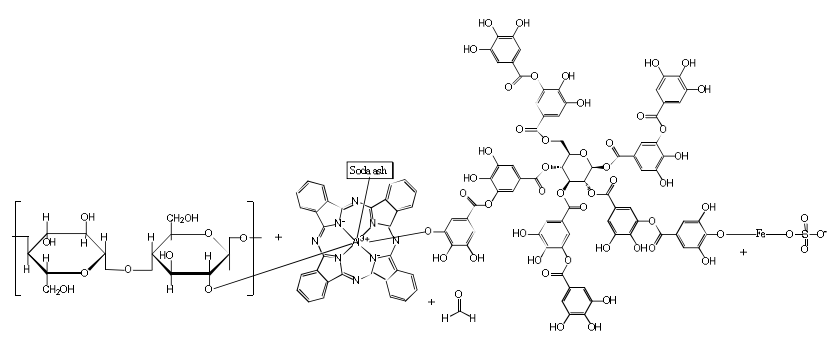

Fig. 11 The interaction of the dyeing process using tannin pigment with iron (II) sulfate fixer

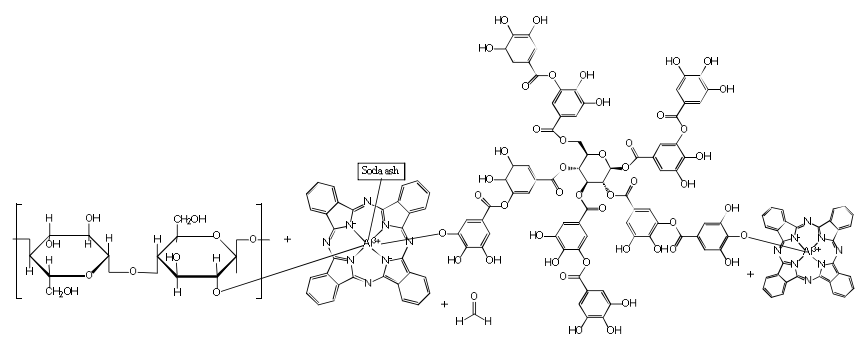

Fig. 12 The interaction of the dyeing process using tannin pigment with alum fixer

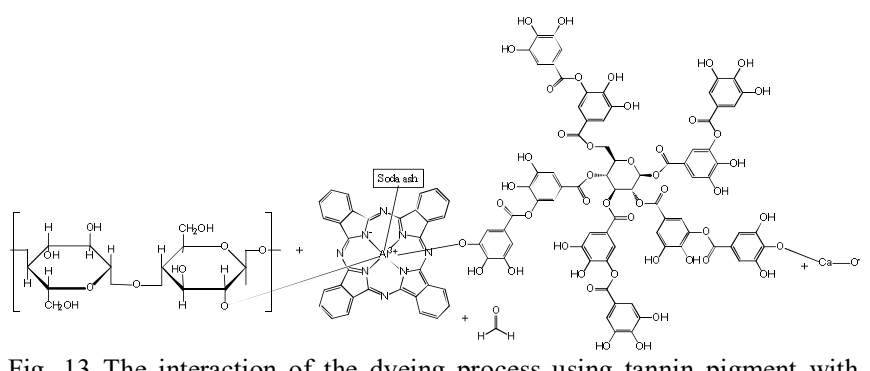

Fig. 13 The interaction of the dyeing process using tannin pigment with calcium oxide fixer 


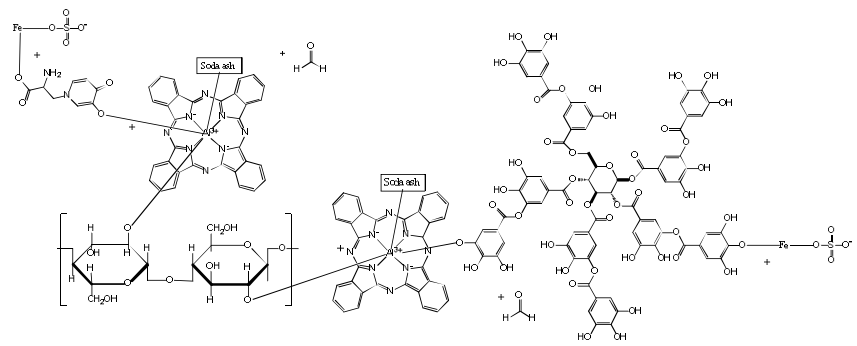

Fig. 14 The interaction of the dyeing process using tannin and mimosine pigment with iron (II) sulfate fixer

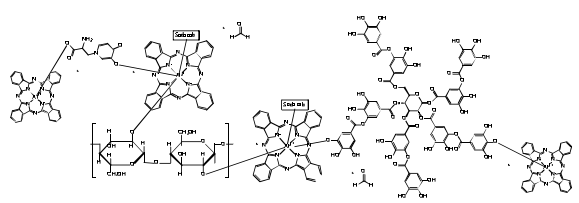

Fig. 15 The interaction of the dyeing process using tannin and mimosine pigment with alum fixer

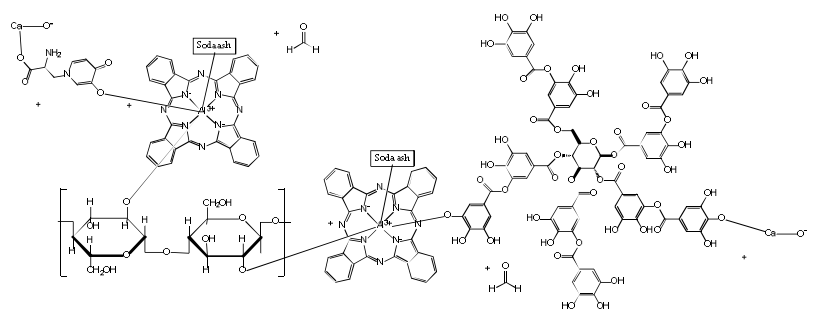

Fig. 16 The interaction of the dyeing process using tannin and mimosine pigment with calcium oxide fixer

\section{CONCLUSIONS}

The cotton dyeing in this study was carried out using natural dyes from an extract of the Sappanwood bark, Cocus Nucifera fiber, and Leucaena leucocephala leaf. It was found that all three had maximum absorption at $540 \mathrm{~nm} ; 384.41 \mathrm{~nm}$; and $417.84 \mathrm{~nm}$; which confirmed the presence of brazilein pigments in the Sappanwood bark extract tannins on the extract of Cocus Nucifera fiber and Leucaena leucocephala leaf. In addition to tannins, mimosine pigment is detected as a tannin companion in Leucaena leucocephala leaf extract characterized by detection of wavelength differences wherein extract of Cocus nucifera fiber Leucaena leucocephala leaf is capable of producing maximum absorption. Increased levels of Cocus Nucifera fiber extract in combination with Sappanwood bark have resulted in specific results on color percentage reflectance, brightness, redness, and yellowness. This condition is associated with an increase in the type and quantity of chromophores and auxochromes in a combination of brazilein and tannin pigments. It has been the same for dyeing using a combination of brazilein pigment with tannin and mimosine from Leucaena leucocephala leaf extract. This condition is associated with the presence of mimosine pigment in addition to tannin in Leucaena leucocephala leaf extract, which has improved the quality of interaction, especially with mordant alum to improve the quality of the resulting dyeing. In addition to the dye composition, applying three different fixer types to this dyeing process has enriched the shades and produced specific colorimetric parameters with significantly affected wash fastness.

\section{ACKNOWLEDGMENT}

The authors are grateful to the Department of Chemistry, Faculty of Mathematics and Science, Universitas Negeri Surabaya for the provision of facilities used in this work.

\section{REFERENCES}

[1] N. Kusumawati, T. Kostiari, and A. B. Santoso, "The influence of washing process using TRO on indigosol dyeing quality, leaching percentage, and mechanical strength of mori fabric," Res. J. Pharm. Biol. Chem. Sci., 2015.

[2] A. Kozlowski, M. Bardecki, and C. Searcy, "Environmental Impacts in the Fashion Industry," J. Corp. Citizsh., 2014, doi: 10.9774/gleaf.4700.2012.sp.00004.

[3] T. Rossi, P. M. S. Silva, L. F. De Moura, M. C. Araújo, J. O. Brito, and H. S. Freeman, "Waste from eucalyptus wood steaming as a natural dye source for textile fibers," J. Clean. Prod., 2017, doi: 10.1016/j.jclepro.2016.12.109.

[4] R. Rame, "Potential of Catalytic Ozonation in Treatment of Industrial Textile Wastewater in Indonesia: Review," J. Ris. Teknol. Pencegah. Pencemaran Ind., vol. 11, no. 1, pp. 1-11, 2020, doi: 10.21771/jrtppi.2020.v11.no1.p1-11.

[5] R. Jamee and R. Siddique, "Biodegradation of synthetic dyes of textile effluent by microorganisms: an environmentally and economically sustainable approach," Eur. J. Microbiol. Immunol., 2019, doi: 10.1556/1886.2019.00018.

[6] S. Islam, "Advance Research in Textile Engineering Reviewing the Sustainability of Natural Dyes," Adv. Res. Text. Eng., vol. 5, no. 2, pp. 1-6, 2020.

[7] L. Amanuel, "Dye Extraction and Cotton Dyeing from Peach Leaf," Curr. Trends Fash. Technol. Text. Eng., 2019, doi: 10.19080/ctftte.2019.05.555661.

[8] N. Kusumawati, A. B. Santoso, M. M. Sianita, and S. Muslim, "Extraction, characterization, and application of natural dyes from the fresh mangosteen (Garcinia mangostana L.) peel," Int. J. Adv. Sci. Eng. Inf. Technol., 2017, doi: 10.18517/ijaseit.7.3.1014.

[9] M. Yusuf, M. Shahid, M. I. Khan, S. A. Khan, M. A. Khan, and F. Mohammad, "Dyeing studies with henna and madder: A research on effect of tin (II) chloride mordant," J. Saudi Chem. Soc., 2015, doi: 10.1016/j.jscs.2011.12.020.

[10] N. Kusumawati, Samik, A. B. Santoso, and S. Muslim, "New natural dyes development: Caesalpinia Sappan L.-Curcuma Longa blended dyes," Rasayan J. Chem., 2020, doi: 10.31788/RJC.2020.1325410.

[11] B. Lellis, C. Z. Fávaro-Polonio, J. A. Pamphile, and J. C. Polonio, "Effects of textile dyes on health and the environment and bioremediation potential of living organisms," Biotechnol. Res. Innov., 2019, doi: 10.1016/j.biori.2019.09.001.

[12] M. Ismail et al., "Pollution, Toxicity and Carcinogenicity of Organic Dyes and their Catalytic Bio-Remediation," Curr. Pharm. Des., 2019, doi: 10.2174/1381612825666191021142026.

[13] M. Berradi et al., "Textile finishing dyes and their impact on aquatic environs," Heliyon. 2019, doi: 10.1016/j.heliyon.2019.e02711.

[14] A. K. Roy Choudhury, "Green chemistry and the textile industry," Text. Prog., 2013, doi: 10.1080/00405167.2013.807601.

[15] S. M. Geelani, S. Ara, N. A. Mir, S. J. A. Bhat, and P. K. Mishra "Dyeing and fastness properties of Quercus robur with natural mordants on natural fibre," Text. Cloth. Sustain., 2017, doi: 10.1186/s40689-016-0019-0.

[16] M. Shabbir, S. U. Islam, M. N. Bukhari, L. J. Rather, M. A. Khan, and F. Mohammad, "Application of Terminalia chebula natural dye on wool fiber-evaluation of color and fastness properties," Text. Cloth. Sustain., 2017, doi: 10.1186/s40689-016-0011-8.

[17] N. Punrattanasin, M. Nakpathom, B. Somboon, N. Narumol, N. Rungruangkitkrai, and R. Mongkholrattanasit, "Silk fabric dyeing with natural dye from mangrove bark (Rhizophora apiculata Blume) extract," Ind. Crops Prod., 2013, doi: 10.1016/j.indcrop.2013.04.041.

[18] N. Kusumawati, S. Samik, A. Budi Santoso, and A. Wijiastuti, "Development of Textile Natural Dyeing using Hybrid Dyes from Mango Leaves Turmeric,” 2018, doi: 10.2991/snk-18.2018.11.

[19] P. Samanta, "A Review on Application of Natural Dyes on Textile Fabrics and Its Revival Strategy," in Chemistry and Technology of Natural and Synthetic Dyes and Pigments, 2020.

[20] A. Mishra and S. Gautam, "Application of Natural Dyes for Herbal Textiles," in Chemistry and Technology of Natural and Synthetic Dyes and Pigments, 2020. 
[21] A. El-Shafei, S. Shaarawy, F. H. Motawe, and R. Refaei, "Herbal extract as an ecofriendly antimicrobial finishing of cotton fabric," Egypt. J. Chem., 2018, doi: 10.21608/EJCHEM.2018.2621.1209.

[22] A. Cerempei, E. I. Mureşan, N. Cimpoeşu, C. Carp-Cărare, and C. Rimbu, "Dyeing and antibacterial properties of aqueous extracts from quince (Cydonia oblonga) leaves," Ind. Crops Prod., 2016, doi: 10.1016/j.indcrop.2016.08.018.

[23] M. M. Kasprzak, A. Erxleben, and J. Ochocki, "Properties and applications of flavonoid metal complexes," RSC Advances. 2015, doi: $10.1039 / \mathrm{c} 5 \mathrm{ra} 05069 \mathrm{c}$.

[24] V. Tangaraj, J. M. Janot, M. Jaber, M. Bechelany, and S. Balme, "Adsorption and photophysical properties of fluorescent dyes over montmorillonite and saponite modified by surfactant," Chemosphere, 2017, doi: 10.1016/j.chemosphere.2017.06.126.

[25] S. Girdthep, J. Sirirak, D. Daranarong, R. Daengngern, and S. Chayabutra, "Physico-chemical characterization of natural lake pigments obtained from Caesalpinia Sappan Linn. and their composite films for poly(lactic acid)-based packaging materials," dye. Pigment., 2018, doi: 10.1016/j.dyepig.2018.04.043.

[26] M. Yusuf, M. Shabbir, and F. Mohammad, "Natural Colorants: Historical, Processing and Sustainable Prospects," Natural Products and Bioprospecting. 2017, doi: 10.1007/s13659-017-0119-9.

[27] Y. P. Devi, "Traditional Natural Dyes Used for Dyeing Fibre and Fabrics of Manipur," vol. 6, no. January, pp. 202-207, 2019.

[28] S. Picco et al., "We are IntechOpen, the world's leading publisher of Open Access books Built by scientists, for scientists TOP $1 \%$," Intech, no. tourism, p. 13, 2016.

[29] M. Ndamunamu, I. Batubara, and L. Sundawati, "Medicinal Plants in East Sumba that Potential as Natural Dyes for Ikat Weaving," J. Kim. Val., 2019, doi: 10.15408/jkv.v5i2.9249.

[30] A. R. Widyasti, A. Lestari, K. Amri, F. Naufal, and K. S. Budiasih, "Pengembangan Standarisasi Pewarna Alami Batik Dari Kulit Kayu Secang (Caesalpinia sappan L.) dengan Teknik Spektroskopi," J. Penelit. Saintek, 2017, doi: 10.21831/jps.v22i1.14850.

[31] A. T. Barat, P. City, and Z. Code, "Utilization of young coconut fibers as textile dyes," pp. 1-8, 2019.

[32] I. A. Samant and D. K. Gaikwad, "Optimization of natural dye extraction from coconut husk," J. Exp. Biol. Agric. Sci., 2020, doi: 10.18006/2020.8(1).54.62.

[33] B. Taif, R. M. Tajuddin, and S. H. Mohd Som, "Dyeing of Silk Fabric with Extract from Caesalpinia Sappan," PEOPLE Int. J. Soc. Sci., 2019, doi: $10.20319 /$ pijss.2019.51.756764.

[34] N. Kusumawati, S. Samik, and S. Muslim, "Extraction and Application of Natural Dyes from Brazilwood and Water guava leaves," 2020, doi: 10.2991/snk-19.2019.10.

[35] L. Ngamwonglumlert, S. Devahastin, N. Chiewchan, and G. S. V. Raghavan, "Color and molecular structure alterations of brazilein extracted from Caesalpinia sappan L. under different $\mathrm{pH}$ and heating conditions," Sci. Rep., 2020, doi: 10.1038/s41598-020-69189-3.

[36] P. Adirestuti, R. Puspadewi, and A. Mardatillah, "Optimization of extraction from sappan wood and its influence on food bacterial contaminants," Indones. J. Pharm. Sci. Technol., vol. 1, no. 1, pp. 2124, 2018.

[37] S. Oontawee, C. Phonprapai, and A. Itharat, "Photo-stabilization of Sappanwood Ethanolic Extract with Ammonium Alum Chelation."

[38] A. G., R. A.J.A., U. R. N. A., and C. Padmalatha, "Toxicological studies of Caesalpinia sappan wood derived dye in Wister albino rats," Food Sci. Hum. Wellness, 2017, doi: 10.1016/j.fshw.2016.10.004.

[39] H. Jiang et al., "Extraction of natural dyes from the stem of Caulis spatholobi and their application on wool," Text. Res. J., 2019, doi: $10.1177 / 0040517519853788$.

[40] A. K. Vardhani, "Caesalpinia sappan L.: REVIEW ARTICLE," Proc. Int. Conf. Appl. Sci. Heal., 2019.

[41] Imalia Dwi Putri, Mardiah, and Soewarno T. Soekarto, "Utilization of Caesalpinia Sappan L. Extraction as A Natural Colorant in Shrimp Paste," Indones. J. Appl. Res., 2020, doi: 10.30997/ijar.v1i2.56.
[42] H. S. Budi, P. Soesilowati, and M. J. Wirasti, "Antibacterial activity of sappan wood (Caesalpinia sappan L.) against aggregatibacter actinomycetemcomitans and porphyromonas gingivalis," Syst. Rev. Pharm., 2020, doi: 10.5530/srp.2020.3.43.

[43] R. Safitri, L. Reniarti, M. Madihah, L. Delia, M. R. A. . Syamsunarno, and R. Panigoro, "The Effect of Sappan Wood Extract (Caesalpinia sappan), Wheat grass and Vitamin E Treatment on the Liver Structure of Iron overload of Rat (Rattus norvegicus)," KnE Life Sci., 2017, doi: 10.18502/kls.v3i6.1159.

[44] N. A. I. Sakir and J. G. Kim, "The effect of sappan wood extracts in treating diabetes induced in mice," Makara J. Heal. Res., 2019, doi: 10.7454/msk.v23i2.10375.

[45] I. Ahmad, A. E. Arifianti, A. S. Sakti, F. C. Saputri, and A. Mun'im, "Simultaneous Natural Deep Eutectic Solvent-Based UltrasonicAssisted Extraction of Bioactive Compounds of Cinnamon Bark and Sappan Wood as a Dipeptidyl Peptidase IV Inhibitor," Molecules, 2020, doi: $10.3390 /$ molecules 25173832 .

[46] H. Seo et al., "In vitro Antitubercular Activity of 3Deoxysappanchalcone Isolated From the Heartwood of Caesalpinia sappan Linn.," Phyther. Res., 2017, doi: 10.1002/ptr.5890.

[47] M. A. O. Mydin, N. M. Zamzani, and A. N. Abdul Ghani, "Influence of elevated temperatures on compressive and flexural strengths of Cocos nucifera Linn. fiber strengthened lightweight foamcrete," Rev. la Constr., 2020, doi: 10.7764/RDLC.19.1.112-126.

[48] "Ministry of Trade of The Republic of Indonesia, Indonesian various Coconut product," 2017.

[49] M. Bolivar-telleria et al., "Second-Generation Bioethanol from Coconut Husk," vol. 2018, 2018.

[50] S. Sarjana and U. Negeri, "Studi pencelupan kain katun menggunbakan ekstraksi sabut kelapa dengan fiksator cuka, gula batu dan air kelapa / Ratna Puspita Dewi," p. 10, 2014.

[51] F. Teknik, U. N. Surabaya, F. Teknik, U. N. Surabaya, and S. B. Barcode, "Pengaruh Frekuensi Celupan Terhadap Hasil Jadi Pewarnaan Batik Nur Tri Anggraini Lutfiyah Hidayati Abstrak Abstract," vol. 03, 2014

[52] N. Kusumawati, A. Kristyanto, and S. Samik, "Exploration of Natural Dyes by Using a Combination of Caesalpinia sappan and Leucaena leucocephala L. Leaves.," 2020, doi: 10.2991/snk-19.2019.9.

[53] A. Manhita et al., "Enlightening the influence of mordant, dyeing technique and photodegradation on the colour hue of textiles dyed with madder - A chromatographic and spectrometric approach," Microchem. J., 2011, doi: 10.1016/j.microc.2010.12.002.

[54] E. Yi and J. Y. Cho, "Color analysis of natural colorant-dyed fabrics," Color Res. Appl., 2008, doi: 10.1002/col.20390.

[55] R. C. Tang, H. Tang, and C. Yang, "Adsorption isotherms and mordant dyeing properties of tea polyphenols on wool, silk, and nylon," Ind. Eng. Chem. Res., 2010, doi: 10.1021/ie100052b.

[56] S. J. Kadolph and K. D. Casselman, "In the bag: Contact natural dyes," Cloth. Text. Res. J., vol. 22, no. 1-2, pp. 15-21, 2004, doi: 10.1177/0887302X0402200103

[57] K. N., M. S., and K. A., "Operational conditions optimization on blacu fabric dyeing technology(case study: Mordanting influence on naphtol color quality and mechanical strength of blacu fiber)," Res. J. Pharm. Biol. Chem. Sci., vol. 7, no. 5, pp. 33-42, 2016.

[58] R. A. A. N. Kusumawati, L. Mufida, Pewarna alami untuk tekstil. Universitas Negeri Surabaya Press, 2018.

[59] N. Kusumawati, S. Samik, and A. Kristyanto, "Quality Improvement of ABBS Hand Writing Batik Production through Standardization of Natural Dyeing using Water Guava and Mango Leaves," 2020, doi: 10.2991/snk-19.2019.8.

[60] S. Samik, A. B. Santoso, and N. Kusumawati, "Diversification of 'NAJWA' Hijab Staining using Tie-Dye Method Based on Natural Dyes," 2020, doi: 10.2991/snk-19.2019.18.

[61] N. Kusumawati, A. B. Santoso, A. Wijiastuti, and S. Muslim, "Extraction, optimization, and dyeing standardization using fresh orange citrus peel on cotton fabrics," Int. J. Adv. Sci. Eng. Inf. Technol., 2020, doi: 10.18517/ijaseit.10.3.3430. 